\title{
Multi-year current time series in the eastern North Atlantic Ocean
}

\author{
by Thomas J. Müller' and Gerold Siedler ${ }^{1}$
}

\begin{abstract}
Time series of currents from an array of 22 subsurface moorings in the Canary and Iberian Basins of the North Atlantic are analyzed with respect to low-frequency variability. The record lengths are usually 1 to 2 years but almost 9 years (site KIEL276, 33N, 22W) in one case. Maximal energies are observed at periods between 50 and 500 days, and high-energy events are found from time to time. The 9-year long series indicates changes in currents with a 3-4 year period, primarily in the zonal component, and anisotropic energy distributions are found for both current components at periods around 200 days. The vertical structure can be well approximated by the barotropic and first-order baroclinic dynamical modes or by one empirical orthogonal function. The regional distribution of spectral properties indicates higher energies in frontal zones and in the neighborhood of the Canary archipelago. In general, the kinetic energy in the month-to-year variability is lower than in the western basins of the North Atlantic.
\end{abstract}

\section{Introduction}

Moorings have become reliable tools for obtaining long time series of current and temperature in the deep ocean. It is now possible to study the oceanic variability on increasingly larger periods, from monthly and annual to interannual changes. In this paper we will present results from a non-coherent array of moorings which were deployed in the Iberian and Canary Basins in the eastern subtropical North Atlantic. Observational periods typically span one or two years, but extend to almost nine years in the present data set on position KIEL276 west of Madeira in the northern Canary Basin.

The area of the measurements (Figures 1 and 2, Table 1) covers the eastern part of the North Atlantic subtropical gyre (see Saunders, 1982; Olbers et al., 1985). The Gulf Stream extension (see Krauss, 1986) includes a branch, the Azores Current (AC), transporting about $10 \times 10^{6} \mathrm{~m}^{3} \mathrm{~s}^{-1}$ in the upper $800 \mathrm{~m}$ across the Mid-Atlantic Ridge south of the Azores between $32^{\circ}$ and $36 \mathrm{~N}$ (Klein and Siedler, 1989). While little or no upper thermocline water enters the Canary Basin from the nearly stagnant zone north of $36 \mathrm{~N}$ (Sy, 1988), the Azores Current provides the main

1. Institut für Meereskunde, University of Kiel, Dusternbrooker Weg 20, D-2300 Kiel, Germany. 


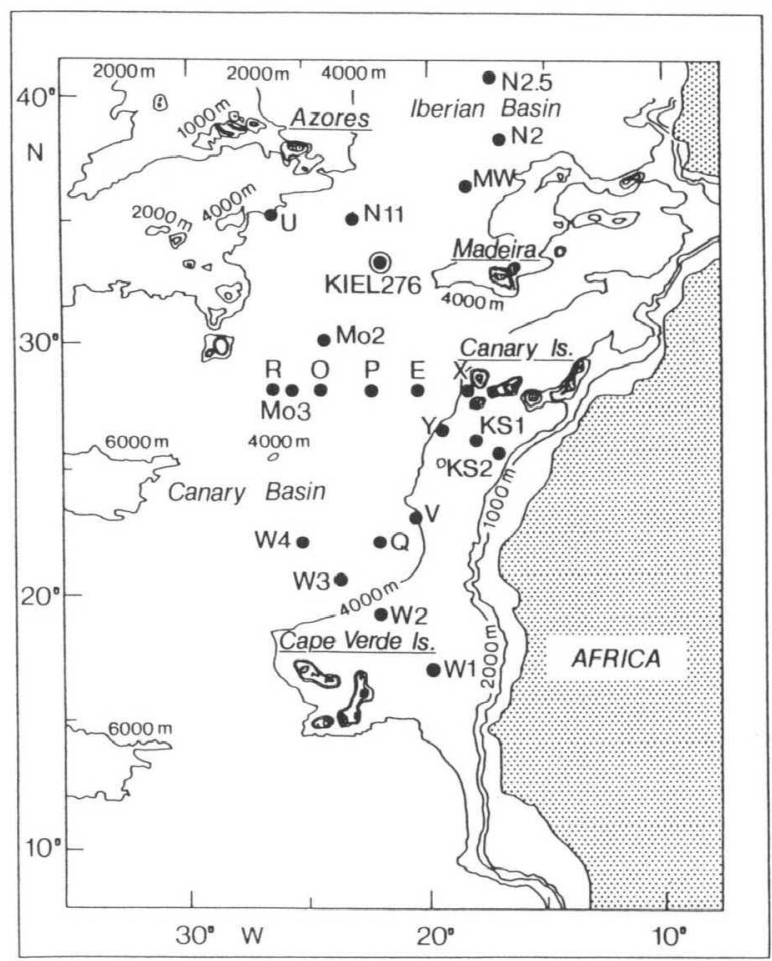

Figure 1. Region of this study with main topographic features and positions of moorings. For details of the moored array see Table 1.

contribution to the subtropical recirculation into the eastern basin (Armi and Stommel, 1983; Stramma, 1984b; Maillard, 1984, 1986; Pollard and Pu, 1985). It partly feeds the Canary Current off the African coast.

Two major frontal zones with distinct current variability form the zonal boundaries of the eastern recirculation cell: the Azores Frontal Zone with the Azores Current in the north (Käse and Siedler, 1982; Gould, 1985; Käse et al., 1986) and the Cape Verde Frontal Zone with the Canary Current/North Equatorial Current (NEC) in the south (Tomczak, 1981; Hagen, 1985; Thiele et al., 1986; Barton, 1987; Zenk et al., 1991). The relationships between geostrophic currents and cross-frontal water mass changes are quite different at these two fronts. Within the Azores Front, no major changes in water masses occur across the front, and the structure of the density field is very similar to that of the temperature and salinity fields. The situation is different at the Cape Verde Front where a major water mass change occurs from North Atlantic to South Atlantic Central Water. Temperature and salinity are almost compensated in density, and the major flows are found just north of this hydrographic boundary (Stramma and Müller, 1989). Different current variability can also be expected at the Mediterranean Water levels in the Upper North Atlantic Deep 


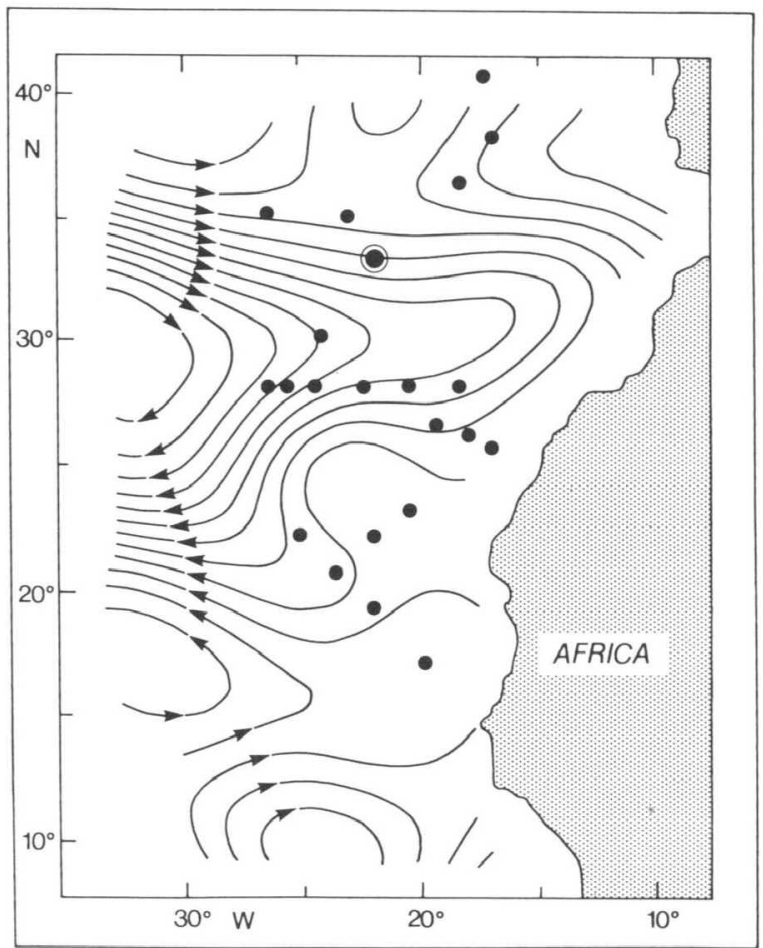

Figure 2. Geostrophic transport streamlines for the layer between 200 and $800 \mathrm{~m}$ as inferred from a historical data set averaged over $3^{\circ} \times 3^{\circ}$ squares (after Stramma and Siedler, 1988). The contour interval is $0.5 \times 10^{6} \mathrm{~m}^{3} \mathrm{~s}^{-1}$, the error is less than $0.6 \times 10^{6} \mathrm{~m}^{3} \mathrm{~s}^{-1}$. Dots indicate the mooring positions of this study (see also Fig. 1 and Table 1).

Water. The weak mean circulation at these depths has a cyclonic pattern in the northern part of our area of study (Defant, 1955; Reid, 1978). It has been shown by Armi and Zenk (1984) and Siedler et al. (1985) that strong circular motion is observed in Mediterranean Water lenses ("Meddies") in the area.

We will be concerned with the characteristic temporal and spatial variability, the energy statistics and the vertical structure of the flow field. Such information is required for calibrating and improving ocean circulation models. Similar studies have been conducted for other mooring sites, e.g. by Schmitz $(1978,1989)$, Schmitz and Hogg (1978), Owens et al. (1982) and Fu et al. (1982) in the western and central North Atlantic, and by Imawaki and Takano (1982), Schmitz (1988) and Niiler and Hall (1988) in the Pacific. Dickson $(1983,1989)$ provided summaries of flow statistics from global sets of mooring data.

Current variability from mooring data in our area of study was investigated earlier by Schmitz et al. (1988) and Vangriesheim (1988), and in the eastern Atlantic along $48 \mathrm{~N}$ by Colin de Verdiere et al. (1989). Mooring data were used to map the deep $(>2000 \mathrm{~m}$ ) mean circulation of the eastern North Atlantic (Dickson et al., 1985). The 
Table 1. Summary of current time series in this study (see Fig. 1). The start time and the duration refer to daily means of low-pass filtered series. The minimum duration is 242 days.

\begin{tabular}{|c|c|c|c|c|c|c|c|}
\hline & $\begin{array}{l}\text { IfM } \\
\text { No. }\end{array}$ & $\begin{array}{l}\text { Latitude } \\
\text { North }\end{array}$ & $\begin{array}{l}\text { Longitude } \\
\text { West }\end{array}$ & $\begin{array}{c}\text { Water } \\
\operatorname{depth} / \mathrm{m}\end{array}$ & Start & $\begin{array}{l}\text { Nominal } \\
\text { duration }\end{array}$ & $\begin{array}{l}\text { Measurement } \\
\text { levels }\end{array}$ \\
\hline $\mathrm{N} 2.5$ & 230 & $40^{\circ} 31^{\prime}$ & $17^{\circ} 19^{\prime}$ & 5310 & 16.05 .78 & 242 & 2 \\
\hline $\mathrm{N} 2$ & $203 / 229$ & $38^{\circ} 00^{\prime}$ & $16^{\circ} 54^{\prime}$ & 5550 & 12.12 .77 & 547 & $3-4$ \\
\hline \multirow[t]{2}{*}{ MW } & $311-1$ & $36^{\circ} 02^{\prime}$ & $18^{\circ} 01^{\prime}$ & 5420 & 05.12 .85 & 325 & 3 \\
\hline & $311-2$ & $36^{\circ} 07^{\prime}$ & $18^{\circ} 20^{\prime}$ & 5507 & 07.11 .87 & 425 & 3 \\
\hline KIEL276 & 276 & $33^{\circ} 06^{\prime}$ & $21^{\circ} 50^{\prime}$ & 5285 & 04.04 .80 & 3204 & $4-8$ \\
\hline N11 & 277 & $34^{\circ} 48^{\prime}$ & $23^{\circ} 05^{\prime}$ & 5155 & 02.08 .81 & 626 & $4-5$ \\
\hline $\mathrm{U}$ & 300 & $35^{\circ} 02^{\prime}$ & $26^{\circ} 29^{\prime}$ & 4000 & 01.11 .84 & 376 & 1 \\
\hline $\mathbf{R}$ & 297 & $28^{\circ} 00^{\prime}$ & $26^{\circ} 30^{\prime}$ & 5035 & 05.11 .84 & 275 & 1 \\
\hline $\mathrm{O}$ & 296 & $28^{\circ} 00^{\prime}$ & $24^{\circ} 28^{\prime}$ & 5161 & 26.10 .83 & 704 & 1 \\
\hline $\mathbf{P}$ & 295 & $27^{\circ} 59^{\prime}$ & $22^{\circ} 23^{\prime}$ & 4860 & 07.11 .84 & 326 & 1 \\
\hline $\mathrm{E}$ & 294 & $28^{\circ} 01^{\prime}$ & $20^{\circ} 23^{\prime}$ & 4619 & 29.10 .83 & 1078 & 1 \\
\hline$X$ & 293 & $28^{\circ} 01^{\prime}$ & $18^{\circ} 20^{\prime}$ & 3432 & 30.10 .83 & 488 & 1 \\
\hline$Y$ & 306 & $26^{\circ} 26^{\prime}$ & $19^{\circ} 25^{\prime}$ & 3878 & 09.10 .85 & 390 & 1 \\
\hline Mo2 & 316 & $31^{\circ} 57^{\prime}$ & $22^{\circ} 50^{\prime}$ & 5390 & 11.11 .87 & 429 & 3 \\
\hline Mo3 & 317 & $27^{\circ} 58^{\prime}$ & $25^{\circ} 38^{\prime}$ & 5300 & 12.11 .87 & 429 & 4 \\
\hline KS1 & 303 & $26^{\circ} 02^{\prime}$ & $18^{\circ} 00^{\prime}$ & 3430 & 15.11 .84 & 323 & 5 \\
\hline KS2 & 304 & $25^{\circ} 33^{\prime}$ & $17^{\circ} 08^{\prime}$ & 3200 & 14.11 .84 & 324 & 3 \\
\hline V & 307 & $22^{\circ} 57^{\prime}$ & $20^{\circ} 31^{\prime}$ & 4179 & 11.10 .85 & 388 & 5 \\
\hline $\mathrm{Q}$ & 308 & $21^{\circ} 59^{\prime}$ & $22^{\circ} 02^{\prime}$ & 4572 & 12.10 .85 & 390 & 4 \\
\hline W1 & 312 & $17^{\circ} 15^{\prime}$ & $20^{\circ} 16^{\prime}$ & 3347 & 20.11 .86 & 368 & 1 \\
\hline \multirow[t]{2}{*}{ W2 } & $309-1$ & $19^{\circ} 02^{\prime}$ & $22^{\circ} 00^{\prime}$ & 3494 & 14.10 .85 & 397 & 3 \\
\hline & $309-2$ & $19^{\circ} 02^{\prime}$ & $21^{\circ} 59^{\prime}$ & 3490 & 25.02 .87 & 265 & 3 \\
\hline W3 & 313 & $20^{\circ} 30^{\prime}$ & $23^{\circ} 37^{\prime}$ & 4561 & 16.11 .86 & 794 & $4-5$ \\
\hline W4 & 314 & $21^{\circ} 56^{\prime}$ & $25^{\circ} 14^{\prime}$ & 5143 & 15.11 .86 & 364 & 4 \\
\hline
\end{tabular}

seasonal current variability in the deep eastern North Atlantic north of $40 \mathrm{~N}$ was studied by Dickson et al. (1982). Part of the data from our mooring KIEL276 (see Fig. 1) was used earlier by Zenk and Müller (1988) to study interannual changes at the Mediterranean Water levels.

In the following we will present our data set, identify wave- and event-type changes on month-to-year time scales and determine the related vertical stucture and statistical properties. The distribution of moorings over a large area will permit us to study spatial variations in frequency spectrum properties, and the long time series at site KIEL276 (the former NEADS1 or N1 position, see Gould, 1983) provides an opportunity to determine current changes on a time scale longer than one year.

\section{The data set}

The analysis is based on time series of ocean currents obtained from a noncoherent set of 22 subsurface mooring sites from late 1977 to early 1989 in the 
Iberian and Canary Basins (Figs 1 and 2). The records had different durations because of the particular scientific objectives of respective experiments, because of logistic requirements, and because of occasional technical problems. We decided to include only records in this study which had a minimum duration of two thirds of a year (actually 242 days was selected). The longest records in our data set originate from the nearly 9-year long time series of mooring KIEL276 in the northern Canary Basin. All the other moorings provide approximately one- or two-year records. The long observations from KIEL276 also have the best vertical resolution, with three instruments in the main thermocline, two at Mediterranean Water levels, and three in the deep layers. Other moorings usually provided data from four or five instruments between the main thermocline and near-bottom layers while some had current meters only at $200 \mathrm{~m}$, with temperature sensors at other depth levels. Information on the moorings is summarized in Table 1.

The design of all these moorings was similar to that of KIEL276 in Figure 3. All uppermost instruments included a pressure sensor to monitor vertical displacements of instruments during strong-current events. The maximum of vertical displacement was typically less than $30 \mathrm{~m}$ during one year, and only in a few cases as large as about $100 \mathrm{~m}$. A worst-case assumption provides an estimate of the resulting maximum horizontal velocity error: with a water depth of $5000 \mathrm{~m}$ and a duration of one day for the onset of a strong-current event, the error in horizontal velocity measurement induced by mooring motion will be less than $1 \mathrm{~cm} / \mathrm{s}$, and will thus be much less than the horizontal velocity related to the event causing such a vertical displacement (a few percent).

Aanderaa RCM4/5 meters were used, with sampling rates of one hour or two hours. In this study we deal only with the low-frequency part of the spectrum with frequencies below inertial. Analyses of the tidal constituents in the high-frequency range of this data set can be found elsewhere (Dick and Siedler, 1985; Siedler and Paul, 1991). The time series in our case were low-pass filtered with a cut-off frequency just below the inertial frequency, and daily means were calculated.

Gaps in the time series occur for two reasons: First, short gaps of typically 3 days exist because of the time between mooring recovery and launching. The missing data can easily be interpolated by cubic splines, ensuring no change of energy levels and phase relations at corresponding time scales (Sturges, 1983). Secondly, gaps of weeks and in some cases months are due to battery problems or instrument failures. These gaps can be filled by vertical interpolation under certain circumstances, using vertical modes. The vertical profiles of Brunt-Väisälä frequency $\mathrm{N}$ required for the dynamical mode computations were obtained from the $3^{\circ} \times 3^{\circ}$ mean temperature and salinity profiles from historical data sets assembled and quality controlled by Siedler and Stramma (1983). This was considered appropriate because of the consistency found between these data and the temperature and salinity profiles obtained in deep CTD casts between mooring recovery and launching. The vertical interpolation 


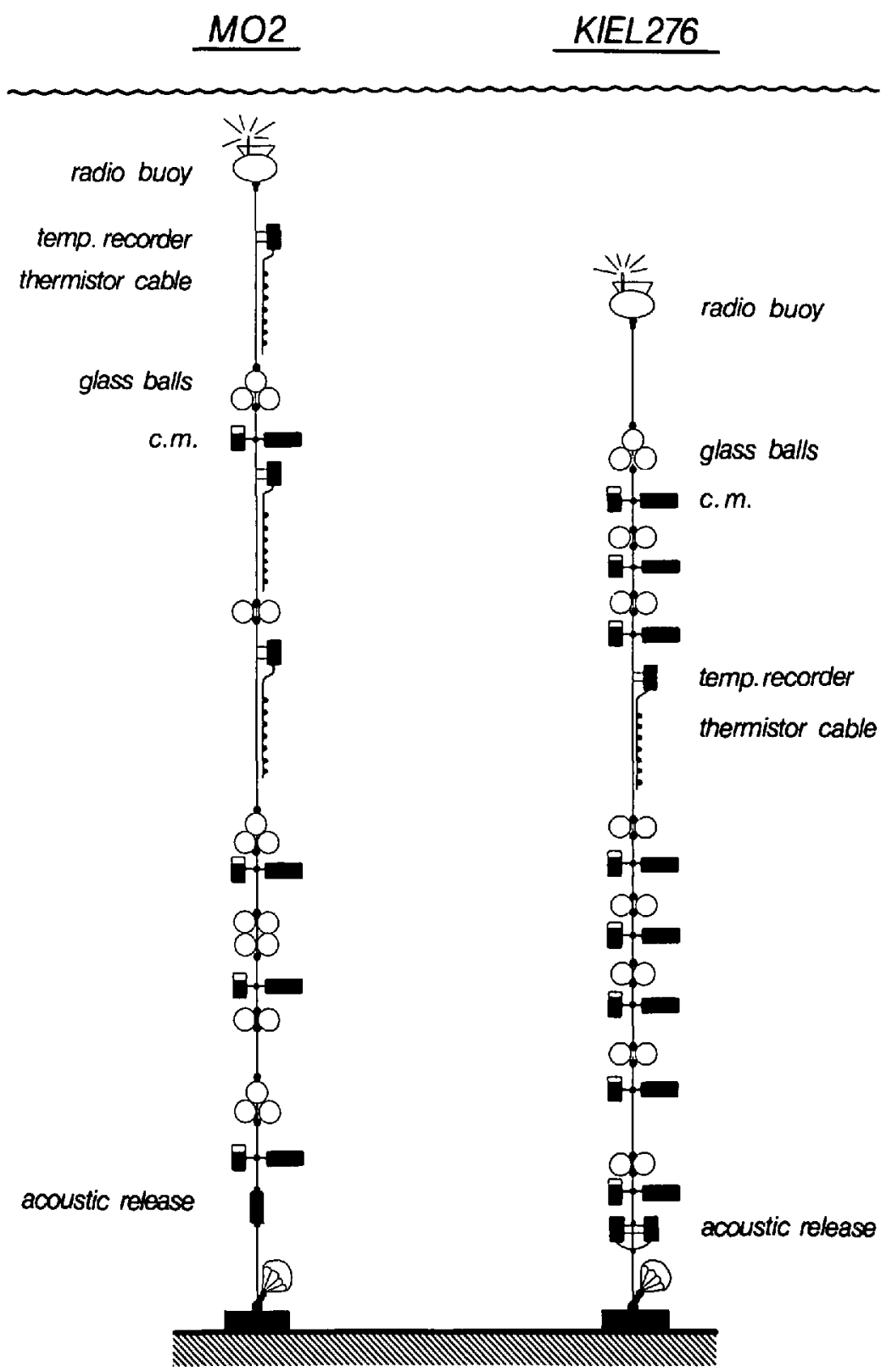

Figure 3. Schematic presentation of two types of current meter (c.m.) moorings in this study.

method was chosen for some records from mooring KIEL276. Details will be described in Section 4. Complete information on the data set has been presented in several data reports (see Müller, 1987; Siedler et al., 1987; Müller et al., 1988, 1990; Zenk et al., 1989). 

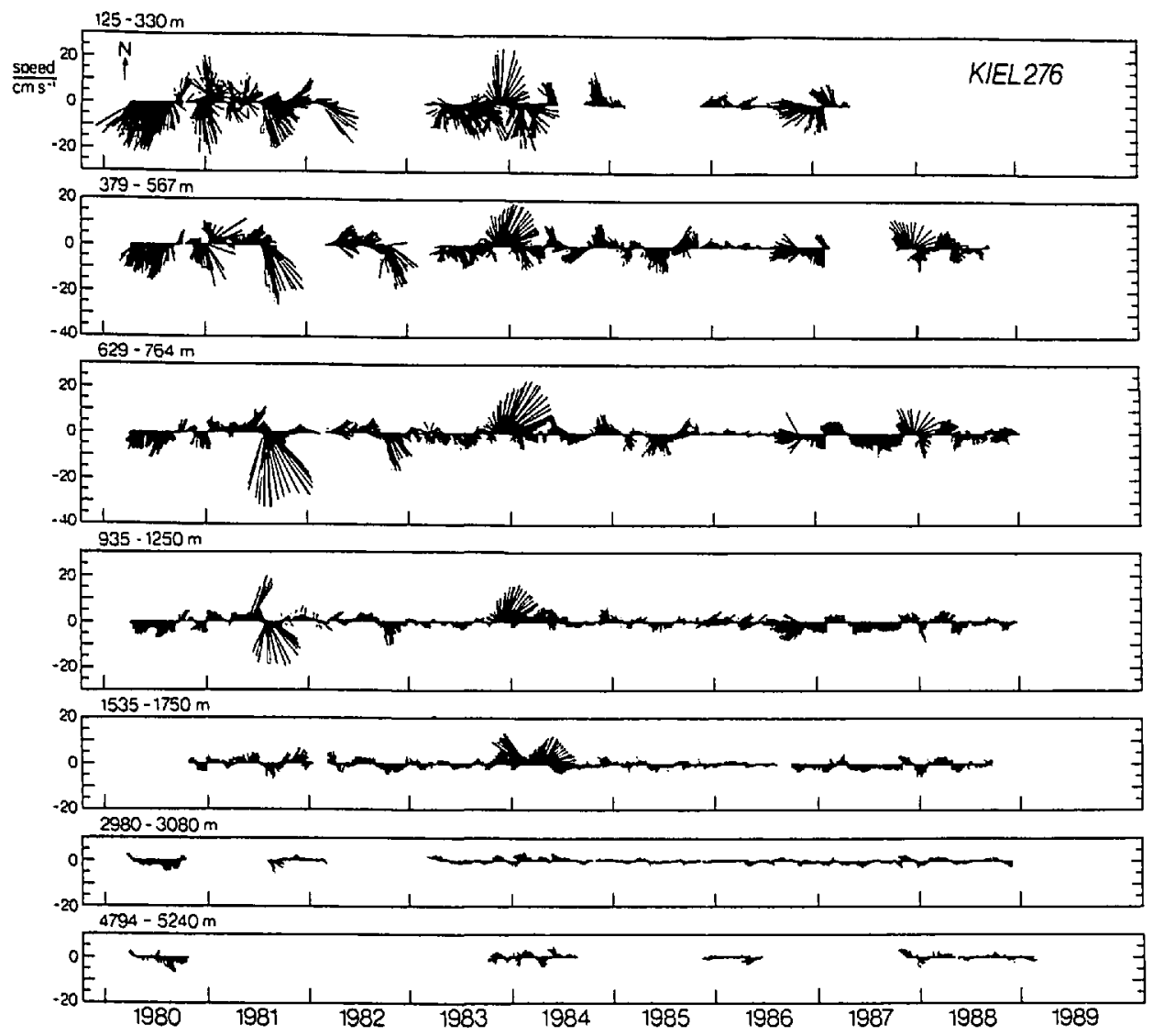

Figure 4. Vector time series of daily means from mooring KIEL276 at indicated depth levels.

\section{Vector time series}

We selected three long records from the total data set to present typical characteristics of the flow in the eastern subtropical basins of the North Atlantic. The composite presentation of vector time series from mooring KIEL276 in Figure 4 summarizes the temporal and vertical variability in the Azores frontal zone over a period of almost 9 years, beginning in April 1980. The mean currents at all depth levels are weak, and the flow is dominated by strong mesoscale events. They occur irregularly and display typical periods of one to three months and maximum amplitudes of $30 \mathrm{~cm} / \mathrm{s}$ in the upper main thermocline. The mesoscale signals can often be recognized throughout the whole water column, suggestive of low-order modal structure, and they are often unidirectional as can be expected for the case of dominating barotropic components. Some of these events have been attributed earlier to displacements of the meandering Azores frontal jet, moving across the observational site from time to time (Siedler et al., 1985). Within the Upper North 


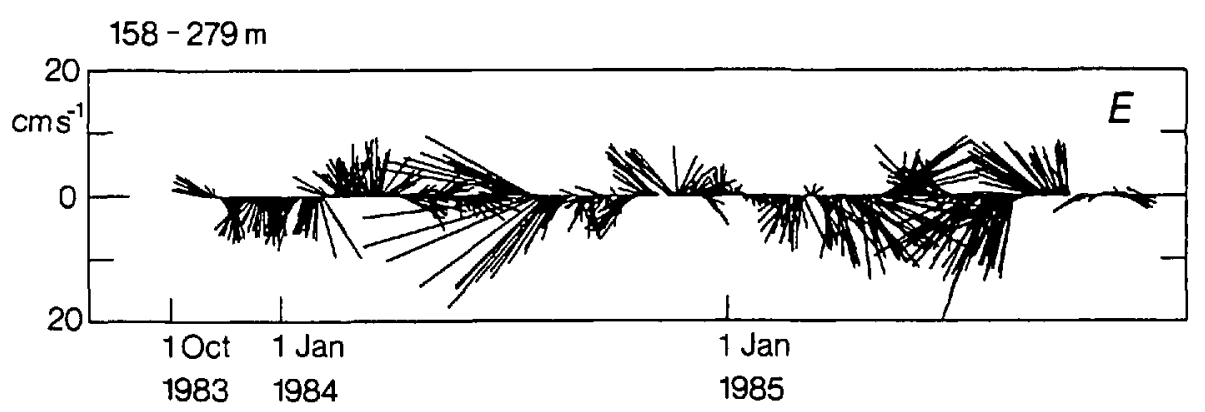

Figure 5. Vector time series of daily means from mooring $\mathrm{E}$ at indicated depth level.

Atlantic Deep Water ( $935 \mathrm{~m}$ to $1250 \mathrm{~m}$ levels) events can sometimes be associated with salty and warm Mediterranean Water lenses (Armi and Zenk, 1984).

Another notable feature of the KIEL276 record is the change in the magnitude of current events from the first half (1980-1984) to the second half (1985-1988) of the observational period. Whereas current speeds reach $25 \mathrm{~cm} / \mathrm{s}$ to $30 \mathrm{~cm} / \mathrm{s}$ during the first four years, they are generally weaker in the second half. The reason for this interannual change has not been identified yet.

Mooring $\mathrm{E}$ west of the Canary Islands was located in the eastern branch of the recirculation pattern (see Figs 1 and 2). The partial current record at a nominal depth of $275 \mathrm{~m}$ shown in Figure 5 has a character similar to the respective record of KIEL276 in Figure 4. It is dominated by events with periods of one to three months and amplitudes of $25 \mathrm{~cm} / \mathrm{s}$ and somewhat weaker variability after autumn 1985. The mean current is only about $1.5 \mathrm{~cm} \mathrm{~s}^{-1}$.

Mooring W3 was placed in the Cape Verde Frontal Zone. Continuous records for two years without major gaps are available at three levels. Owing to the loss of the main buoyancy at the top of the mooring in August 1988 (broken line in Fig. 6) the instrument depths increased by $100 \mathrm{~m}$ on the upper levels. The effect on the records was marginal. The spectral characteristics of current and temperature did not change at tidal and inertial periods and indicated only slightly less energy at longer periods. This could be expected for larger depths in the main thermocline (see Figure 15 in Zenk et al., 1989). Signals with 3-month periods prevail at this site. The near-bottom record at $4505 \mathrm{~m}$ depth is dominated by higher-frequency signals. Onken and Klein (1991) explained this vertical variation in spectral shape, with a large contribution at periods of a few months in the upper ocean as a result of baroclinic instability effects and a flattened spectrum in the deep layers where topographic Rossby waves dominate.

\section{Vertical structure}

The vertical structure of the observed currents will be described by vertical modes, but only those sites will be considered where good vertical resolution can be achieved 

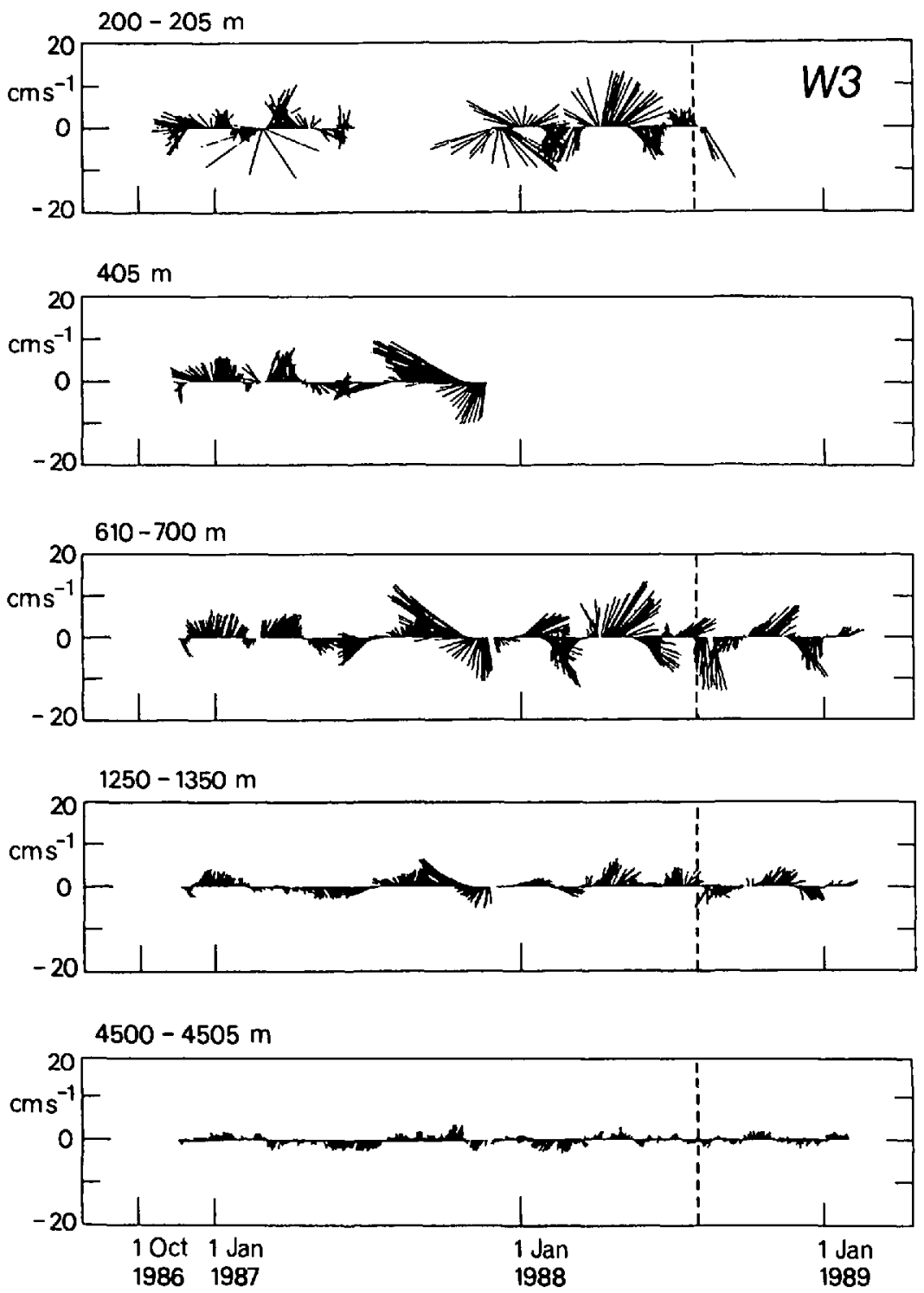

Figure 6. Vector time series of daily means from mooring W3 at given depth levels. The vertical broken lines indicate the time of buoyancy loss causing an increase in depths of instruments.

on the basis of four or more current meter levels. This applies to moorings KIEL276, N11, KS1, KS2, V, Q and W3. We will use two different approaches. First, we will apply the theory of linearized quasi-geostrophic flow. The "dynamical modes" describe the solutions of such a dynamical system. We will show later that only a few low-order dynamical modes are required to obtain a good approximation of the 
vertical flow structure. Although this is suggestive of quasi-geostrophic dynamics, one has to keep in mind that this consistency does not necessarily indicate that the flow indeed obeys such dynamics. Any system of orthogonal functions could be selected to fit the data (Richman et al., 1977). We will also use these modes for interpolating data gaps in the vertical.

Secondly we will describe the data by empirical orthogonal functions (EOFs) which do not have any dynamic implications, but simply serve as statistical tools. The vertical structure of the empirical and dynamical modes will then be compared to each other in those cases where the number of degrees of freedom is sufficiently high. This is best fulfilled for KIEL276 with simultaneous records from up to 8 levels.

Temperature data are not included in this comparison for two reasons. First, within the linear quasi-geostrophic frame and in the absence of horizontal temperature advection due to geostrophic motion, temperature fluctuations are related to the divergence of the quasi-geostrophic flow, a quantity which cannot be calculated from our noncoherent array. Secondly, temperature changes due to winter convection in the northern part of the area (Siedler et al., 1987) and mixing processes in the Cape Verde Frontal Zone further south (Zenk et al., 1991) contaminate the temperature record related to a quasi-geostrophic flow field (see Müller, 1987).

The theory of linear quasi-geostrophic motion with zero mean over flat bottom at mid-latitudes leads to the equation for the vertical structure of the horizontal flow components (see Pedlosky, 1979):

$$
\frac{d}{d z}\left(\frac{f^{2}}{N^{2}(z)} \frac{d F_{m}}{d z}\right)+\lambda_{m}^{2} F_{m}(z)=0
$$

with the rigid-lid boundary conditions at the surface $(z=0)$ and the bottom $(z=-H)$

$$
\frac{d F_{m}}{d z}=0 \quad \text { for } z=0,-H
$$

Note that these equations also hold for the gravity mode at frequencies much less than the mean stability frequency $N$ (LeBlond and Mysak, 1978).

The only parameters in Eqs. (1) are the Coriolis parameter $f$, the Brunt-Väisälä frequency $N(z)$ to be calculated from the mean stratification and the water depth $H$. When solving (1) for mooring KIEL276 numerically, a complete set of orthonormal functions $F_{m}(z)$, the dynamical modes, is obtained for that position. The first three functions are displayed in Figure 7. The first baroclinic mode $(m=1)$ goes through zero near $1500 \mathrm{~m}$, close to the level which Stramma (1984b) found as a reference level in his analysis of the mean geostrophic flow field, and it of course has the maximum at the surface. The vertical shear of the mean geostrophically balanced flow (Stramma, 1984b) resembles the shear in the first baroclinic mode. We therefore use it as a reference function for interpolation purposes. The second baroclinic mode $(m=2)$ has its maximum slightly below the $1000-\mathrm{m}$ level, corresponding to the 

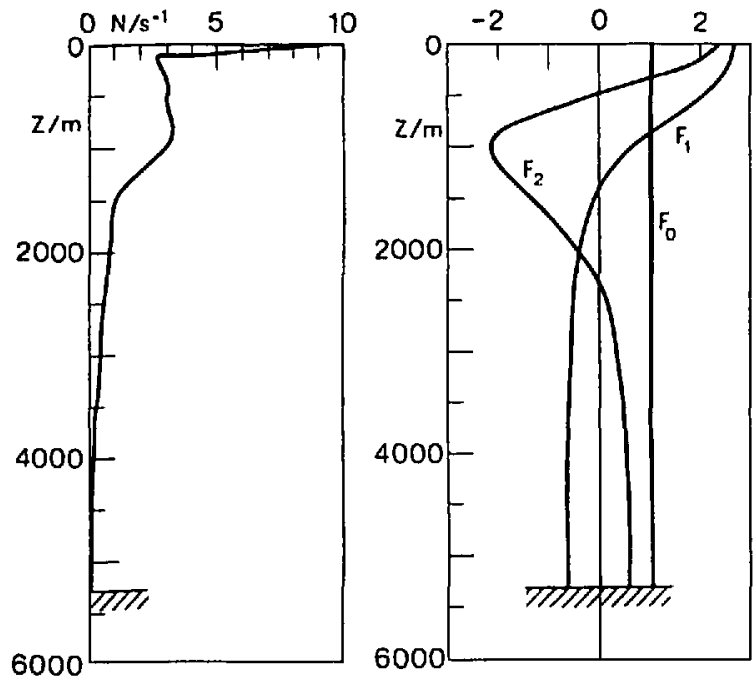

Figure 7. Mean vertical profiles of the Brunt-Väisälä frequency $(N)$ at the location of mooring KIEL276 and barotropic $\left(F_{o}\right)$ and first two baroclinic dynamical modes $\left(F_{1}, F_{2}\right)$ fitted to the data from this mooring and normalized by total energy of each mode.

Mediterranean outflow water layers. We therefore expect this mode to be important in the case of events related to Meddies.

In order to describe the statistics of the vertical structure of the flow without assumptions regarding the dynamics, an EOF analysis (see McWilliams and Shen, 1980) was performed. Following standard EOF theory (Lorenz, 1959) we decompose the fluctuations around the sample mean of the horizontal current vector $\mathbf{u}^{\prime}\left(t, z_{i}\right)$ measured at $N$ discrete depths $z_{i}$ of a setting into a statistical (time dependent) and a deterministic (depth dependent) part.

$$
\mathbf{u}^{\prime}\left(t, z_{i}\right)=\sum_{n=1}^{N} \mathbf{A}_{n}(t) E_{n}\left(z_{i}\right)
$$

The functions $E_{n}(z)$ are the EOFs. They are determined as the orthonormal set of eigenvectors of the covariance matrix $\mathrm{C}$ of the data with elements

$$
c_{i j}=\overline{\mathbf{u}^{\prime}\left(t, z_{i}\right) \cdot \mathbf{u}^{\prime}\left(t, z_{j}\right)} \cdot \sqrt{h_{i} h_{j}} .
$$

Here the overbar denotes time-averaging and the weighting factors $h_{i}$ are the depth intervals associated with the current meters. We recall that the sum of the trace elements $c_{i i}$ is proportional to the total energy in the records times a factor $1 / 2$, that the eigenvalues associated with an EOF equals the vertically integrated variance of the $\mathrm{EOF}$, and that the sum of all eigenvalues equals the total vertically integrated variance in the records. By the scalar product in (4) we assure that the most energetic components are vertically related. We calculated the EOFs and associated eigenvalues for all mooring periods in the Azores Front, the Canary Current and the Cape 

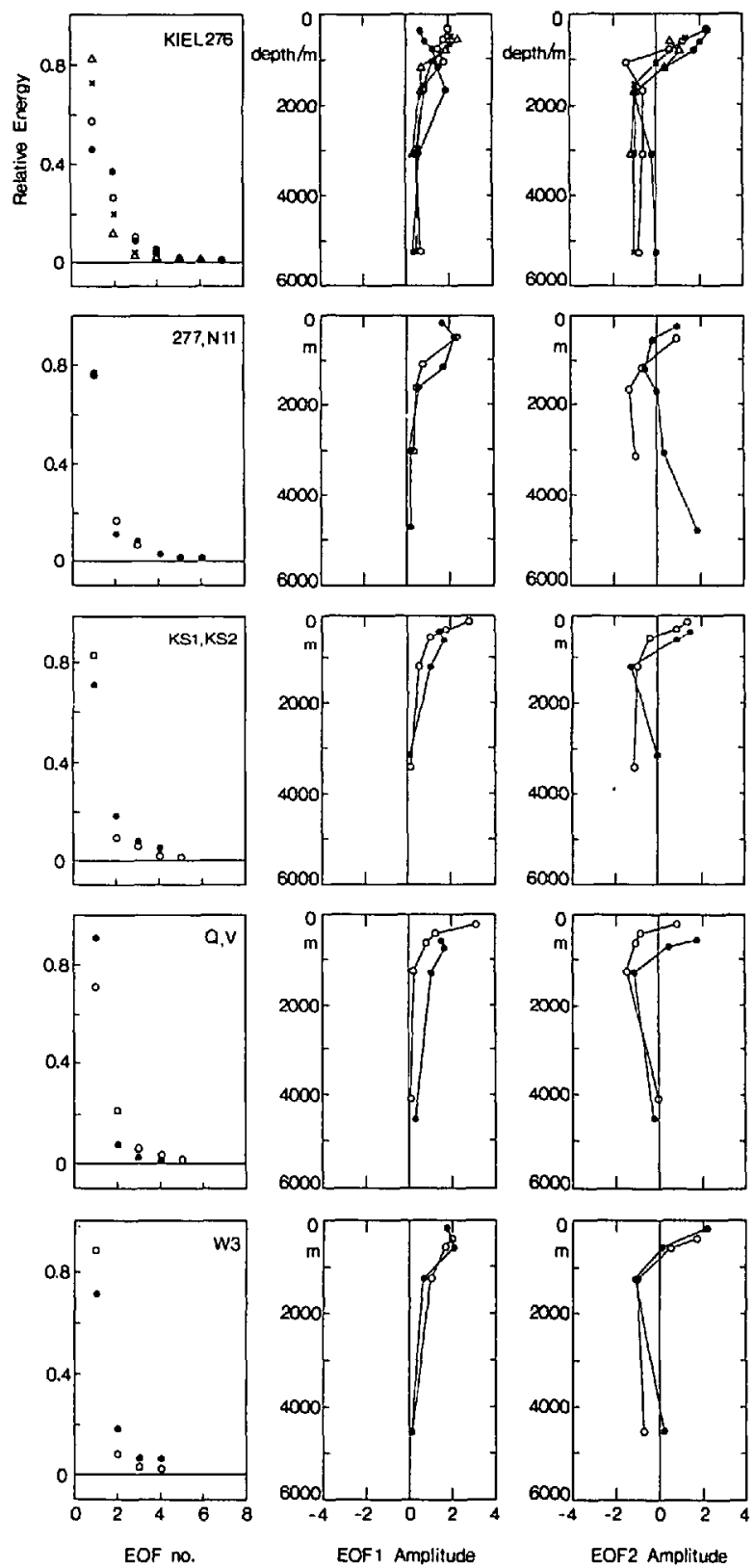

Figure 8. Empirical orthogonal functions of order 1 (EOF1) and order 2 (EOF2) and contributions of EOFs to the total energy as a function of EOF number.

Verde Frontal Zone where the following conditions were fulfilled: full depth coverage with a minimum of four current meters, including at least one instrument in the Mediterranean water level and one in the deep ocean and with a common record length of at least half a year. The results are shown in Figure 8 for the Azores Front 
(sites KIEL276 and N11), the Canary Current (KS1, KS2 and $V, Q$ ) and the Cape Verde Frontal Zone (W3). With two exceptions (moorings 276-5 and 276-7) the first EOF represents more than $70 \%$ of the energy; the first two EOFs together always add up to more than $85 \%$, also in the case when more than four records from different depths are available. The third and higher-order EOFs together contain only half or even less than half the energy of the second mode. They are thus energetically unimportant and will not be discussed further.

The shape of the first EOF is generally similar to the shape of the first-order baroclinic mode, with a maximum in the upper $600 \mathrm{~m}$. Only one exception exists. This is mooring KIEL276-5 where a maximum is found at $1600 \mathrm{~m}$. It is caused by a particular event occuring in May 1984. None of all the other EOFs has a zerocrossing. It can be seen in the time series of the amplitudes of the dynamical modes (not presented here) that the barotropic and first-order baroclinic modes are coupled during the most-energetic events. The barotropic component is strong enough during such events to prevent a reversal of the flow direction in the vertical which would otherwise be caused by higher-order modes.

The second EOF has a zero-crossing in the upper thermocline at all sites, with the maximum found between $1000 \mathrm{~m}$ and $1500 \mathrm{~m}$, decreasing amplitudes at deeper levels and sometimes with a second zero-crossing. Its shape usually resembles a superposition of the first two baroclinic modes. There are cases where the second baroclinic mode dominates the second EOF. They can be related to Meddies. Similar structures of the most energetic EOFs were observed elsewhere, e.g. during the MODE experiment in the western Atlantic (McWilliams and Shen, 1980) and also in the Drake Passage (Inoue, 1985).

The similarity between the EOFs and the dynamical modes is consistent with the good least-square approximation of the first EOF by the barotropic and the first two baroclinic modes at KIEL276. We have a sufficiently large number of degrees of freedom for such a fit in this case. The barotropic and the first baroclinic modes clearly dominate with respect to total energy, and the relative error is below $5 \%$ when fitting the first EOF with four to six records. In fitting the second EOF the second dynamical mode becomes more important. Although the signal-to-noise ratio is much smaller in this case, the approximation error is only of order $10 \%$ (Müller, 1987). We conclude that the statistical properties of the records at KIEL276 as documented by EOFs are consistent with the representation by the dynamical modes. As mentioned at the beginning of this section this does not, however, explain which particular physical process is responsible for the observed structure (Richman et al., 1977).

The dynamical modes $F_{m}(z)$ as derived from Eqs. (1) and (2) will now be used to decompose the current time series $\mathbf{u}\left(t, z_{i}\right)$ into time series of modal amplitudes $\mathbf{u}_{m}(t)$ by

$$
\mathbf{u}\left(t, z_{i}\right)=\sum_{m=0}^{M} \mathbf{u}_{m}(t) F_{m}\left(z_{i}\right)+\mathbf{r}\left(t, z_{i}\right)
$$


KIEL276
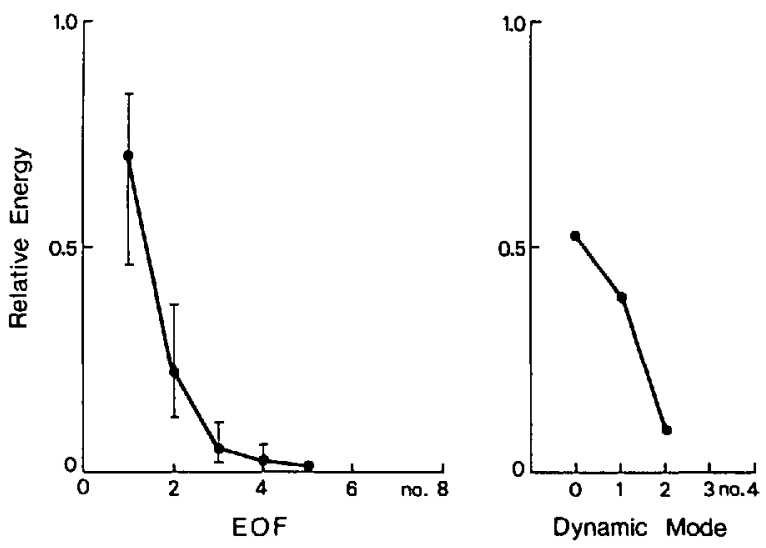

Figure 9. Contributions of different order of EOFs and dynamical modes to total energy. Standard deviations of EOFs are indicated.

The noise $\mathbf{r}\left(t, z_{i}\right)$ at depth $z_{i}$ is weighted by the variance of the corresponding record and then minimized in the least-square sense for each time step and each component, resulting in the time-dependent dynamical modal amplitudes. In earlier tests it was established (Müller, 1987) that a good approximation of the vertical current structure is obtained from the sum of the barotropic and the first two baroclinic modes. The approximation is not improved significantly by the inclusion of higher modes. This supports the conclusion from the above EOF-analysis.

The skill was better than $70 \%$ for all observational periods at KIEL276 with at least two degrees of freedom in the approximation procedure (i.e. five or more instruments). This again supports the conclusion that a decomposition into loworder dynamical modes provides a good approximation of the vertical current structure. The relative contributions of the EOFs and the dynamical modes are presented in Figure 9. Two thirds of the low-frequency energy can be described by using only one EOF or two dynamical modes.

It was mentioned before that dynamical modes can be used for vertical interpolation when filling data gaps. Müller (1987) used extrapolated time series with a minimum duration of 112 days in eight tests for a comparison with corresponding measured time series at that depth. These had not been included for the modal decomposition. The energy spectra did not differ significantly within $95 \%$ confidence intervals, and the coherence was well above the zero level for periods larger than 10 days, increasing to longer periods. The phase was close to zero. Almost all the correlation coefficients were larger than twice the level for zero-correlation. These results provide confidence in using the dynamical mode approach for the vertical interpolation of gaps in the KIEL276 series and at the $260 \mathrm{~m}$ level of N11. 


\section{Statistics}

A selection of basic statistical values for the current components $u$ (east) and $v$ (north) is presented in Tables A1 to A5 in the Appendix. The standard notation for means and second order moments is used. FKE is the fluctuating part of vector variance or the kinetic energy per unit mass, $s$ is the directional stability of the flow defined by the ratio of the magnitude of the mean vector to the mean speed (Dickson et al., 1985). Note that a unidirectional flow $(s=1)$ results in a straight line in a progressive vector diagram, while flow with $s=0$ leads to a closed curve. Also given is the angle $\phi_{\mathrm{FKE}}$ defined by the direction where the respective current component has its maximum variance. It can only be significantly different from other directions when the eddy momentum flux $\overline{u^{\prime} v^{\prime}}$ is significantly different from zero.

All error estimates refer to the $95 \%$ confidence limits of the estimated statistical moment. Two assumptions are made in the calculations. First, it is assumed that the time series have normal distributions around the means. This is not always fulfilled, but such an assumption may provide a first approximation. Secondly, the number of degrees of freedom in a series is estimated from the ratio of its length and its integral time scale, where the latter was calculated from the integration of the series auto-correlation function to its first zero-crossing. This method assures both, a conservative estimate of the number of degrees of freedom and also comparability with earlier statistical analyses (Luyten, 1982, Dickson et al., 1985; see also Flierl and McWilliams (1977) for a more detailed discussion of the error analysis). Some values from our data set were already reported by Dickson (1989) in his compilation of eddy statistics of world ocean currents. These values are included here for completeness, together with information on integral time scales, flow stability and main direction of vector variance.

Error bounds are given for all estimates of mean currents in Tables A1 to A5. Lower and upper limits relative to the mean of variances are presented for both flow components at selected sites and depths in Table 2 . The error bounds are relatively narrow at mooring KIEL276 with its long series in the Azores Front. They are typically 0.7 and 1.5 , respectively, for both components at that location. At all other sites the series are shorter and the error limits therefore wider apart, with typical values of 0.5 and 1.6 (sometimes up to 2.0).

We will first discuss the stability of statistical estimates. In their analysis of the mean flow in deep ( $>2000 \mathrm{~m}$ ) eastern North Atlantic Dickson et al. (1985) noted the extremely long-term variations at the $3000 \mathrm{~m}$ level of KIEL276 (N1 in their notation). At the Miditerranean Water level of $1000 \mathrm{~m}$, Zenk and Müller (1988) found similar long-term fluctuations, with a reversal of the flow after three years and a mean near zero in $6 \frac{1}{2}$ years of record. Their results are consistent with those of Schmitz et al. (1988) who obtained 2-year records at 32N, 24W, close to the site of KIEL276. These authors noted strong year-to-year variability at the selected observational depths (470 m, $1070 \mathrm{~m}, 3070 \mathrm{~m})$. 
Table 2. Error bounds (95\% confidence) $e_{u u}$ and $e_{v y}$ for east $(u)$ and north (v) components, respectively. Values are normalized by the variance for selected sites and depths.

$\begin{array}{lcccc}\begin{array}{l}\text { Mooring site } \\ \text { IfM No. }\end{array} & \begin{array}{c}\text { Depth } \\ (\mathrm{m})\end{array} & \begin{array}{c}\text { Duration } \\ (\mathrm{d})\end{array} & e_{u u} & e_{v v} \\ \text { Iberian Basin } & & & & \\ \text { N2.5/230-1 } & 485 & 242 & 0.4,3.7 & 0.5,3.0 \\ \text { N2/203 } & 788 & 547 & 0.6,2.2 & 0.6,2.4 \\ & 1668 & 413 & 0.5,2.0 & 0.5,2.3 \\ & 3168 & 689^{5} & 0.3,2.0 & 0.3,2.0 \\ \text { Azores Front } & & & & \\ \text { KIEL276 } & 250 & 3204 & 0.7,1.5 & 0.8,1.3 \\ & 450 & 3204 & 0.7,1.6 & 0.8,1.3 \\ & 670 & 3204 & 0.7,1.7 & 0.8,1.3 \\ & 1000 & 3204 & 0.7,1.6 & 0.8,1.3 \\ & 1600 & 3204 & 0.7,1.3 & 0.7,1.3 \\ & 3000 & 2057 & 0.8,1.3 & 0.8,1.3 \\ \text { 28N section } & 5185 & 429 & 0.7,1.5 & 0.7,1.6 \\ \text { O/296 } & 5240 & 306 & 0.6,2.0 & 0.7,1.1 \\ \text { E/294 } & & & & \\ \text { Canary Current region } & & 704 & 0.6,2.2 & 0.7,1.5 \\ \text { KS1/303-1 } & 240 & 1078 & 0.7,1.5 & 0.7,1.4 \\ & 165 & & & \\ \text { V/307-1 } & 1215 & 323 & 0.6,2.2 & 0.6,1.9 \\ & 3400 & 323 & 0.7,2.3 & 0.7,2.4 \\ & 458 & 323 & 0.5,1.5 & 0.7,1.3 \\ & 1292 & 388 & 0.6,1.7 & 0.6,1.8 \\ \text { Cape Verde } & 4094 & 388 & 0.6,1.8 & 0.6,1.8 \\ & & 355 & 0.7,1.3 & 0.7,1.6\end{array}$

Cape Verde

Frontal Zone

W3/313

$\begin{array}{cc}405 & 365 \\ 1250-1350 & 794 \\ 4500 & 794\end{array}$

$\begin{array}{ll}0.6,2.3 & 0.6,1.8 \\ 0.6,2.0 & 0.8,1.6 \\ 0.8,1.6 & 0.7,1.5\end{array}$

sCombined from two series of $422 \mathrm{~d}$ and $267 \mathrm{~d}$ duration, respectively.

We take the first $5 \frac{1}{2}$ years of the KIEL276 current record from $670 \mathrm{~m}$ depth where the data base is best to get some insight into the long-term stability of basic statistical values. In Figure 10 we show the integral time scales, the fluctuating part of kinetic energy, the means of both components and the flow-stability parameters as a function of the length of the averaging interval. The averaging increment is 30 days. The most striking feature is the large fluctuation of the integral time scale associated with the zonal flow component. An oscillation with a 3-4 year period of the zonal component may be responsible (see Section 6 and Fig. 15). The mean of the east component changes sign even after integrating over more than $1 \frac{1}{2}$ years. In the 


\section{KIEL276, 670m}
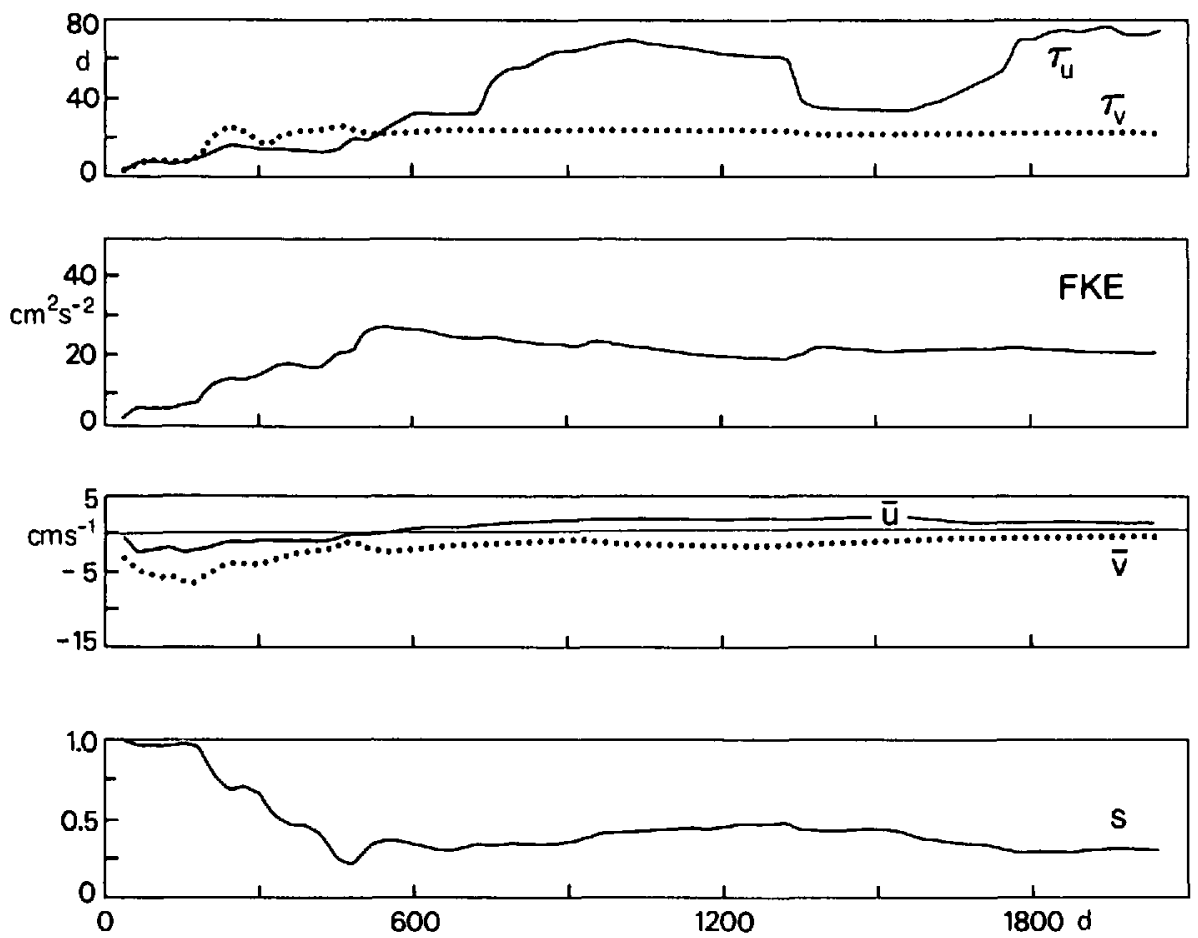

Figure 10. Integral time scales $\left(\tau_{u}, \tau_{v}\right)$ of east and north components, respectively, fluctuating part of kinetic energy (FKE), current components $(\bar{u}, \bar{v})$ and stability parameter $(s)$ at site KIEL276 averaged over record lengths of $30,60,90$ days etc.

meridional components the integral time scale becomes stable after two years. Both components as well as FKE and $s$ are almost stable after three years although the error bounds are still large due to long period variability. Schmitz (1989) reported drastic changes in the basic statistics of 20-month (1984-1986) current records at the Mid Ocean Dynamics (MODE) site centered at $28 \mathrm{~N}, 70 \mathrm{~W}$ in the western subtropical Atlantic. He compared his results with corresponding measurements from the first experiment at this site in the 1970s (The MODE Group, 1978). He also claimed to have identified interannual changes, which may be due to slight displacements in the subtropical front. The weak stability of statistical estimates in our results should be kept in mind when discussing the statistics of the flow.

The integral time scale of the east component in the upper thermocline at KIEL276 is 75 days after $81 / 2$ years (Table A2). This value is extremely large when compared with integral time scales from all other positions in our array and also when compared with integral time scales from other studies in the deep eastern basin (Dickson et al., 1985) and in the western basin (Wunsch, 1983; Owens et al., 1982). An exception is provided by the results from MODE where Richman et al. (1977) 
reported a similar integral time scale also in the east component. There appears to be a dominance of motion at longer periods in currents at "interior" ocean sites like those from MODE or KIEL276 with eddy activity at lower levels than in boundary currents or over rough topography. It may also be that the Azores Front shifts its position across KIEL276 infrequently, thus causing long-time changes in the front's main direction, i.e. in the east component. The north component will then be dominated by currents associated with the shorter eddy scale.

The zonal integral time scale at KIEL276 decreases to lower values at deeper levels and reaches the scales typical for meridional components at the $1600 \mathrm{~m}$ level, namely 18 days. Similar values, 10 to 30 days, are calculated for both components at all other sites in the main thermocline of our data set. At depths of $3000 \mathrm{~m}$ and beyond the integral time scales decrease slightly to values between 7 and 23 days over abyssal plains (KIEL276). Even lower values of 2 to 14 days are obtained in regions where the bottom topography may cause higher-frequency variability which can mask the lower-frequency signals dominating in the main thermocline (Sites KS1, KS2, V, $\mathrm{Q}$ and the W-array; see also Onken and Klein, 1991). We are not able to predict whether the integral time scales of the upper ocean zonal components would increase if longer records were available.

We will next turn to the fluctuating part of the kinetic energy (FKE). The variances of zonal and meridional components are calculated for the maximal record lengths $\tau$ for each site. They represent kinetic energies per unit mass contained in the frequency band between $1 / 2 \mathrm{~d}^{-1}$ and $1 /(2 \tau)$ where $2 \tau$ is larger than 488 days. Within this frequency range, zonal and meridional variances typically do not differ by more than a factor of 0.6 to 1.7 at all sites and depths. These differenes are generally insignificant with respect to $95 \%$ error bounds, not shown here. Only in the period range from 50 to 500 days at KIEL276 we find anisotropy. Taking the whole period range, however, we obtain isotropic variance distributions within the $95 \%$ confidence limits. At this point we therefore proceed from the assumption that the overall low-frequency current field is approximately isotropic and therefore simply use the fluctuating part of kinetic energy or vector variance (FKE).

As noted earlier by Dickson $(1983,1989)$ FKE is much lower in the eastern than in the western subtropical basins of the North Atlantic, and it varies regionally and with depth. In the layer between $150 \mathrm{~m}$ and $300 \mathrm{~m}$ at the Azores Front (Sites KIEL276, $\mathrm{N} 11$ and $U$ ) FKE has a value near $30 \mathrm{~cm}^{2} \mathrm{~s}^{-2}$. This is less by a factor of 3 than the value at the comparable western Atlantic MODE Site. At $450 \mathrm{~m}$ (KIEL276) and $540 \mathrm{~m}$ (N11) FKE drops to 20 to $25 \mathrm{~cm}^{2} \mathrm{~s}^{-2}$, still by a factor of 2 to 2.5 smaller than at the same depth in MODE. The level of FKE is only slightly less and rather uniform (20 to $27 \mathrm{~cm}^{2} \mathrm{~s}^{-2}$ ) in the interior flow of the upper main thermocline at these depth levels north (N2.5) and south (R, O, P, E, Y, Mo2, Mo3) of the Azores Front. In contrast, an eddy-resolving model including the Azores Front predicted values which are lower by a factor of 3 to 6 in the upper thermocline (Spall, 1990). 
The upper thermocline FKE increases to approximately $70 \mathrm{~cm}^{2} \mathrm{~s}^{-2}$ close to the Canary Islands (X) and close to the origin of the Canary Current (KS1, KS2). The maximum value of $104 \mathrm{~cm}^{2} \mathrm{~s}^{-2}$ in this layer is observed at site $V$ well within the Canary Current regime. Even this high FKE is small when compared with values at sites south of the North Atlantic Current along $48^{\circ} \mathrm{N}$ (see Colin de Verdière et al., 1989). Further south near the water mass boundary of the Cape Verde Frontal Zone the level drops to 20 to $30 \mathrm{~cm}^{2} \mathrm{~s}^{-2}$, a level which was also found in the western Atlantic at the northern boundary of the North Equatorial Current in the POLYMODE cluster $\mathrm{C}(16 \mathrm{~N}, 54 \mathrm{~W})$ (see Fu et al., 1982).

In the eastern basins we expect low-frequency variability in the depth range from $750 \mathrm{~m}$ to $1300 \mathrm{~m}$ to be strongly influenced by the Mediterranean outflow and the associated mesoscale intra-thermocline eddies. From the above model one obtains energy levels near 2 to $3 \mathrm{~cm}^{2} \mathrm{~s}^{-2}$ at $1125 \mathrm{~m}$ depth, with a maximum of 4 to $5 \mathrm{~cm}^{2} \mathrm{~s}^{-2}$ in the Azores frontal region (Spall, 1990). Our measurements indicate somewhat higher values ( 4 to $10 \mathrm{~cm}^{2} \mathrm{~s}^{-2}$ ) in the range $750 \mathrm{~m}$ to $1300 \mathrm{~m}$, with the highest values in the Azores Front at KIEL276. FKE is about $1 \mathrm{~cm}^{2} \mathrm{~s}^{-2}$ in the deep eastern North Atlantic ( $3000 \mathrm{~m}$ to $3500 \mathrm{~m}$ ), with almost uniform distribution. FKE only increases to up to $3 \mathrm{~cm}^{2} \mathrm{~s}^{-2}$ close to the bottom at the Azores Front. FKE is smaller by a factor of about 5 to 6 when comparing with energy levels in the western basins.

Despite the fact that FKE is small at all depths and sites in the subtropical eastern Atlantic, the variable components dominate the mean flow everywhere by a factor of at least 5 in energy. This explains the difficulties one encounters when attempting to determine the mean in the time series. Eddy fluxes are generally weak and close to or below significance levels.

Despite the difficulties in determining the means, we will attempt a comparison between our estimates from moored data and those obtained by other methods. In Figure 11 we present the vertical distribution of directly-observed mean currents within the thermocline at KIEL276, together with the geostrophic current profile calculated from mean hydrographic data in a $3^{\circ} \times 3^{\circ}$ square centered at that site (after Stramma, 1984b). The zero-crossings of both directly measured components are found near $1300 \mathrm{~m}$. This supports the level of no motion at that position as inferred by Stramma (1984b) and Klein and Siedler (1989). These authors used an approach including water mass property distributions and a mass-conservation scheme proposed by Fiadeiro and Veronis (1982). The vertical shear is much stronger in the north component of the observed mean currents when compared to the geostrophic currents. This is probably due to the large-scale averaging on $3^{\circ} \times 3^{\circ}$ squares applied to the hydrographic data set.

Assuming $100 \mathrm{~km}$ as the width of the Azores Front (see Käse and Sielder, 1982) we calculate a transport between the surface and $1300 \mathrm{~m}$ of $2.0 \times 10^{6} \mathrm{~m}^{3} \mathrm{~s}^{-1}$ to the southeast. This compares well to the geostrophic transport in that $3^{\circ} \times 3^{\circ}$ square of $2.1 \times 10^{6} \mathrm{~m}^{3} \mathrm{~s}^{-1}$ derived from Stramma's (1984a) data. This southeastward transport, 


\section{KIEL276}
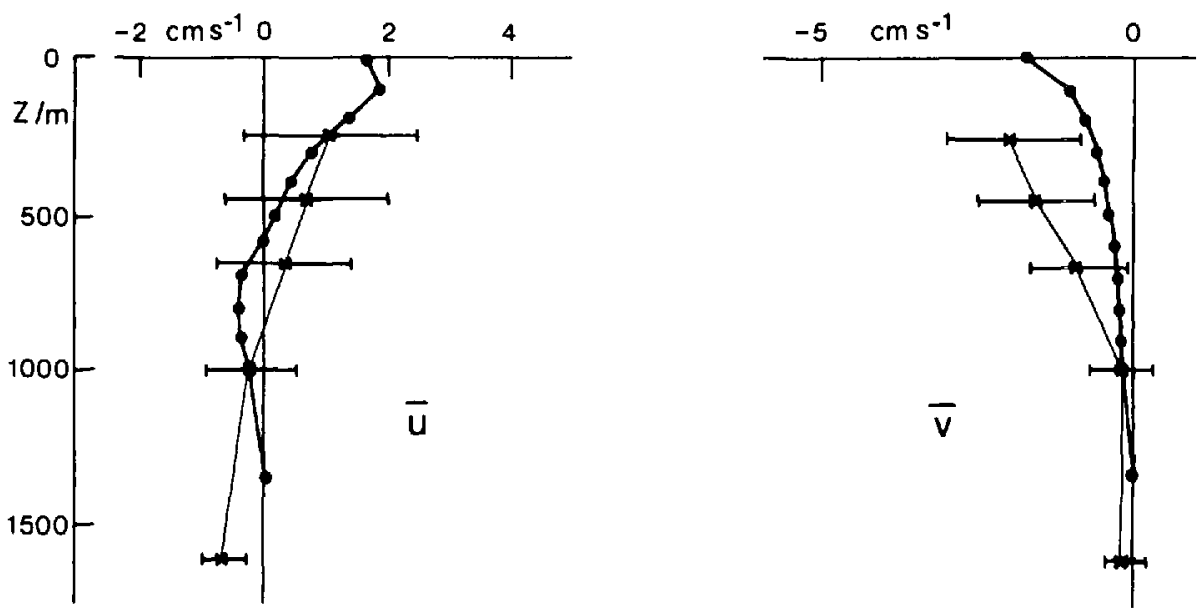

Figure 11. Vertical distribution of mean geostrophic flow (dots) from hydrographic data averaged over $3^{\circ} \times 3^{\circ}$ squares (after Stramma, 1984a) and directly measured flow at mooring KIEL276 (crosses) from this study. The bars indicate $95 \%$ confidence limits.

however, differs in magnitude and direction from the Sverdrup transport of $3 \times$ $10^{6} \mathrm{~m}^{3} \mathrm{~s}^{-1}$ to the south calculated by Isemer and Hasse (1987). Apparently the large-scale Sverdrup transport can be masked regionally by other phenomena like the Azores frontal jet flow.

Stramma (1984a) also gave the horizontal pattern of mean flow vectors using a historical data set averaged on $3^{\circ} \times 3^{\circ}$ squares and a reference level determined with the method of Fiadeiro and Veronis (1982) and water mass distributions. We compare his distribution of the flow at $200 \mathrm{~m}$ with the mean current vectors from the moored observations at similar depth levels (see Tables A1 to A5) in Figure 12. Whereas the directions, with a few exceptions, are usually consistent, the direct measurements lead generally to higher speeds than the geostrophic estimates. This again may be caused by the large-scale averaging of the hydrographic data.

Finally we will assume that the means from observations at $200 \mathrm{~m}$ along $28 \mathrm{~N}$, between $26^{\circ} 30^{\prime} \mathrm{W}$ and the Canary Islands (Sites $\mathrm{R}$ to $\mathrm{X}$ ), represent the currents from the surface down to $200 \mathrm{~m}$. We then estimate a transport of $3.3 \times 10^{6} \mathrm{~m}^{3} \mathrm{~s}^{-1}$ between $\mathrm{R}$ and $\mathrm{X}$ to the southsouthwest, compared to $2.0 \times 10^{6} \mathrm{~m}^{3} \mathrm{~s}^{-1}$ in the geostrophic transport to the southwest across that section from Stramma's historical data set. The Ekman transport (Stramma and Isemer, 1988) calculated for a $1^{\circ}$ strip between $R$ and $X$ is small $\left(0.7 \times 10^{6} \mathrm{~m}^{3} \mathrm{~s}^{-1}\right)$ and directed to the westnorthwest depending on the season. Our current meters were below the Ekman layer and were therefore not affected by Ekman currents. A drifter data set from Krauss and Käse (1984) leads to a much larger transport at this section, namely $9.6 \times 10^{6} \mathrm{~m}^{3} \mathrm{~s}^{-1}$. We believe that their estimates are too high due to direct wind effects and Stokes drift. Considering the 


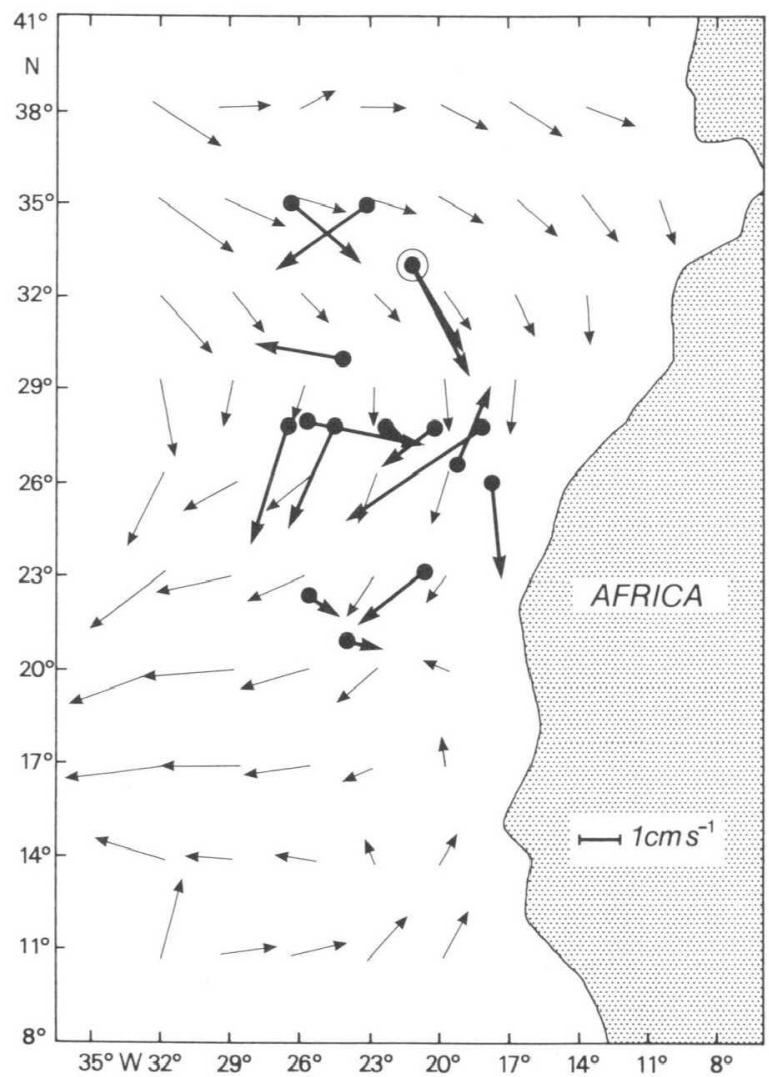

Figure 12. Mean geostrophic currents at $200 \mathrm{~m}$ from hydrographic data in $3^{\circ} \times 3^{\circ}$ squares (thin arrows, after Stramma, 1984a) and mean currents from moored instruments at similar depth levels (thick arrows).

fact that these drifters were launched north of our study area more than 6 months earlier, it can be expected that several drifters will have lost their drogues before reaching the observational area and will therefore be driven by the surface winds. We conclude that the usual reference level of $1300 \mathrm{~m}$ near KIEL276 is consistent with direct measurements, but that geostrophic transports calculated from average density fields are generally lower than transports obtained from direct measurements.

\section{Energy at low frequencies}

The long time series available in the present study permit the compilation of low-frequency spectra and the distinction between mesoscale and annual or interannual variability (see also Schmitz, 1978). The longest series are available from KIEL276 and provide information down to frequencies of $5.5 \mathrm{y}^{-1}$. As an example, spectra of velocity components at $450 \mathrm{~m}$ depth from that site are presented in Figure 13. The log-log-spectra indicate isotropy in the range between 1/100 and 

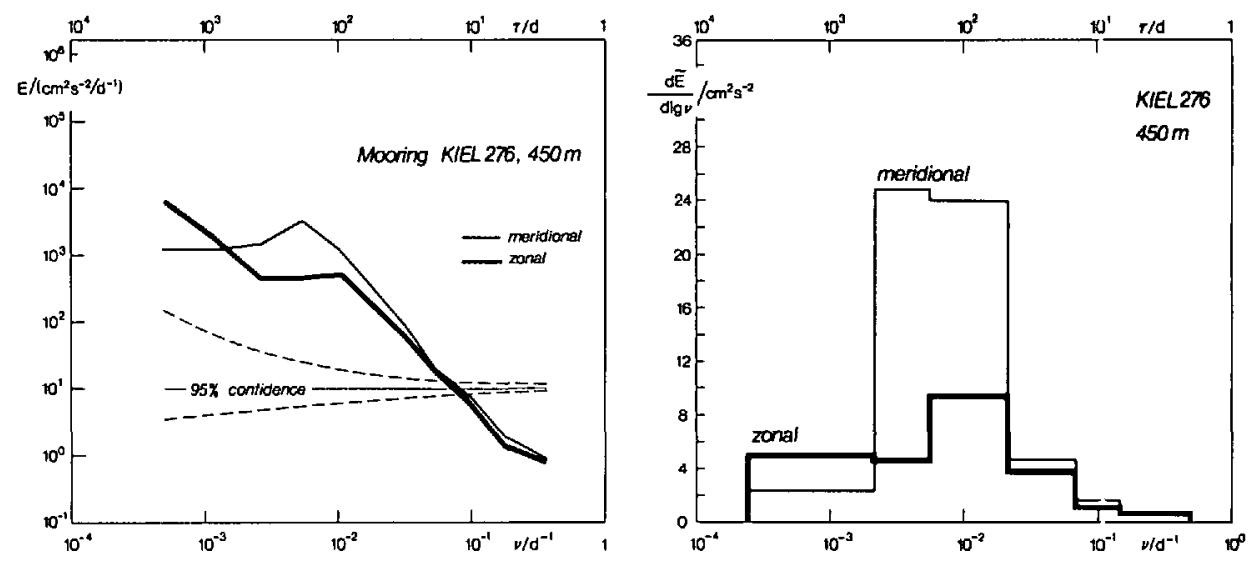

Figure 13. Frequency spectra for zonal $(u)$ and meridional $(v)$ velocity components in the main thermocline at KIEL276. Log-log-spectra are given on the left side and corresponding energy-preserving spectra are displayed on the right side. $E=$ kinetic energy density per mass, $\bar{E}=$ kinetic energy per mass, $\nu=$ frequency, $\tau=$ period.

$1 / 2 \mathrm{~d}^{-1}$. This result has also been found in the shorter time series at the other sites of this study (see also Müller, 1987). Spectra of east and north components do not differ significantly in shape between different depths and sites in this frequency range. As known from other locations in the world ocean (e.g. Richman et al., 1977; Wunsch, 1981,1983 ) spectra in this range are "red" with an approximate slope of -2 .

We find a different result when inspecting the lower frequencies in the range 1/800 to $1 / 100 \mathrm{~d}^{-1}$. The spectra flatten towards these lower frequencies, and the slope even reverses. The flow is anisotropic here, with the meridional component being more energetic than the zonal component. It should be noted that the difference between the two components at the peak near $1 / 200 \mathrm{~d}^{-1}$ only just exceeds the $95 \%$ confidence interval. The two spectral curves will, however, be clearly significant with respect to a $90 \%$ confidence interval (not shown here). In order to identify the actual contributions to the total kinetic energy in the low-frequency range, the spectra are replotted in energy-preserving form in Figure 13 on the right side. We find maximum energy in the range between $1 / 500$ and $1 / 50 \mathrm{~d}^{-1}$, and the zonal component has less than one third of the energy found for the meridional component. Schmitz et al. (1988) presented spectra from a 2-year record at 32N, $24 \mathrm{~W}$, near KIEL276. In their 470-m series they also find an excess of the meridional over the zonal variance in the $1 / 150$ to $1 / 20 \mathrm{~d}^{-1}$ frequency band, but with a ratio of 2 .

When inspecting our results in Figure 13 at even lower frequencies, we find a reversal of the magnitude ratio, with larger zonal than meridional component energy. The differences between components cannot, however, be verified in this frequency range due to a large confidence interval (see Fig. 13a). We will show further below, however, that visual inspection of low-passed time series appears to support this result. 

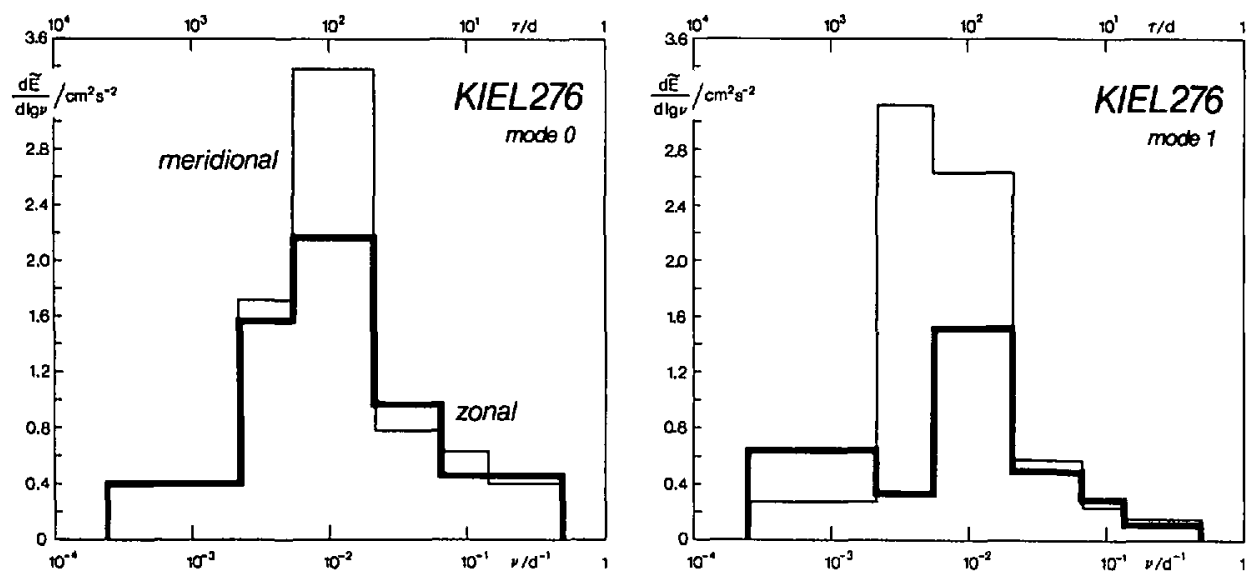

Figure 14. Energy-preserving spectra of zonal $(u)$ and meridional $(v)$ components of barotropic (0) and first-order baroclinic (1) modes at KIEL276.

The energy-preserving spectra of the barotropic and the first-order baroclinic dynamical modes are presented in Figure 14. The total low-frequency energy is of similar magnitude for both modes, but the spectral properties deviate. The barotropic mode is characterized by a fairly narrow peak near a frequency of $1 / 100 \mathrm{~d}^{-1}$ which is most pronounced in the meridional component and has similar magnitudes of zonal and meridional components in the interannual band. The baroclinic mode has a broader energetic range with high energy, and also higher energy levels are found in the meridional than in the zonal components in the mesoscale band and a reversal of the ratio of meridional to zonal energies at very low frequencies.

Anisotropy in the low-frequency flow variability was predicted in a model by Lippert and Käse (1985). Using the model wind spectra of Müller and Frankignoul (1981) as forcing and a flat-bottom ocean with an eastern boundary they obtained a similar anisotropy in the Rossby wave motion as a result of resonant baroclinic interaction.

As mentioned before, even in the long time series of KIEL276 the interannual changes cannot be identified in spectra with sufficiently good confidence. We will therefore turn to the visual inspection of appropriately low-passed time series. In Figure 15 we present time series of 180-day means, overlapped by 91 days, of zonal and meridional components of the $450 \mathrm{~m}$-current and of the barotropic and firstorder baroclinic modes. There is a striking difference between the east and north component series with respect to the dominating periods. In the east components one recognizes a very slow change while the north component appears to be dominated by lower-period changes.

One possible explanation for the different behavior of the zonal and meridional flow at these very long periods may be provided by the recognition that the site is close to the meandering Azores front, with a jet-like flow as part of the subtropical 

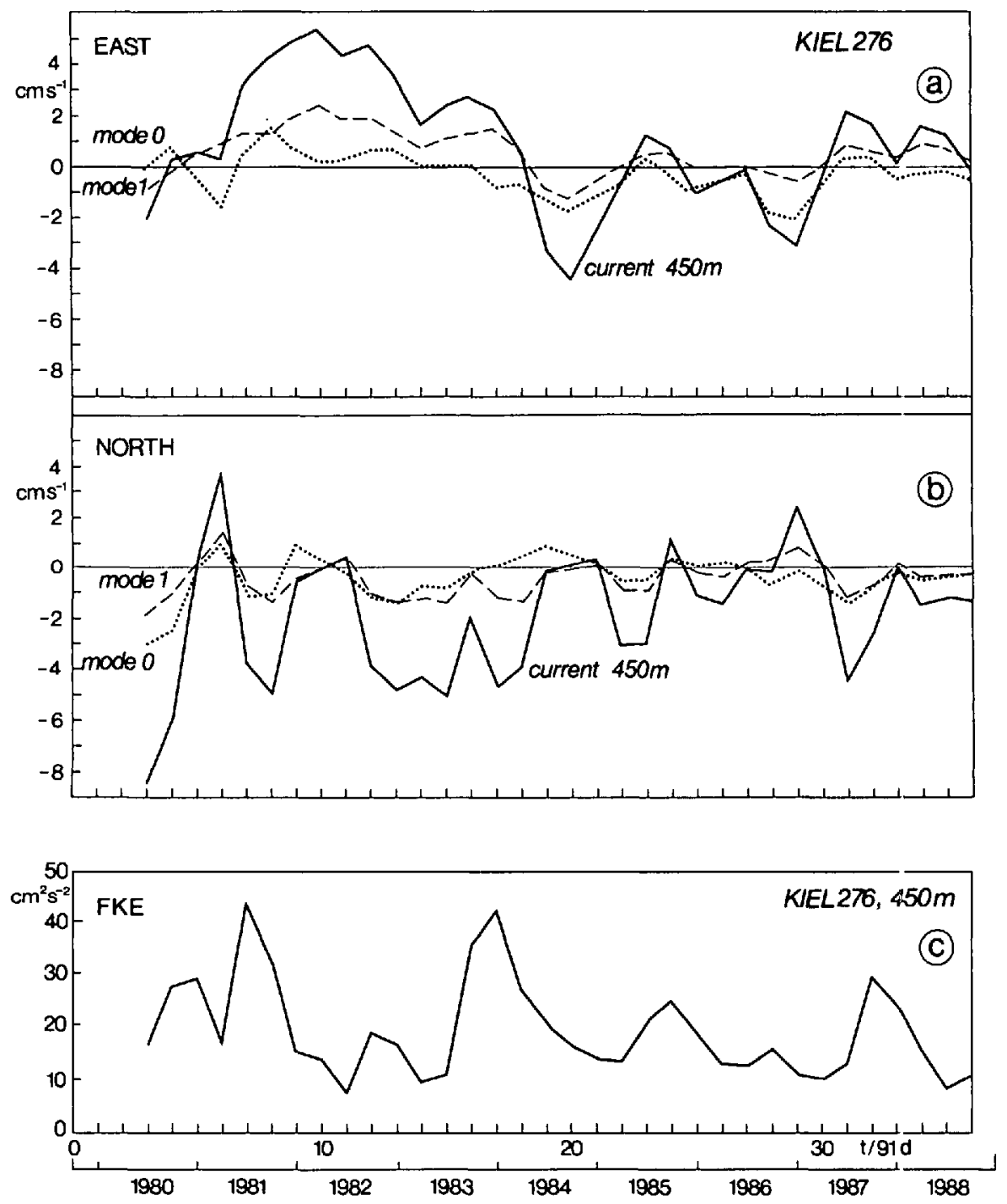

Figure 15. Time series of 180-day means, overlapped by 91 days, of (a) zonal (EAST) and (b) meridional (NORTH) components of the 450-m current and the barotropic (0) and first-order (1) baroclinic modes at KIEL276, and (c) time series of the fluctuating part (FKE) of kinetic energy per mass, obtained as the variance of the 180-day partial series.

gyre. The zonal flow will be essentially along the front and may be dominated by long time scale changes of the frontal jet intensity while the meridional flow will be more affected by vortices related to the front. It is possible, however, that this phenomenon is not just related to the local front, but rather to larger-scale gyre undulations. Cox (1987) in his North Atlantic circulation model found a series of equatorward flows proceeding from east to west across the subtropical gyre at the speed of the first 
baroclinic mode and with periods of 4 to 4.5 years. That model did not include a temporal variability in boundary conditions. A time-varying wind stress representing the observed seasonal variations at the eastern boundary will generate propagating Rossby waves and thus add energy in the semiannual to annual period range, consistent with our observations (Krauss and Wübber, 1982; Hermann and Krauss, 1989).

The vector variance FKE at $450 \mathrm{~m}$ relative to the low-passed time series is also shown in Figure 15. This fluctuating part describes the mesoscale variability in the range from $2 \mathrm{~d}$ to $1 \mathrm{yr}$. We find events with energies exceeding the typical levels by a factor of up to 3. The first half of the record from 1980 to 1984 includes more high-energy peaks than the second half. The two main events $(1981,1983 / 84)$ are due to Meddies moving past the mooring site (Armi and Zenk, 1984; Siedler et al., 1985; Käse et al., 1986).

A seasonal signal can neither be identified in currents nor in FKE. This also holds for other depths and sites and also for monthly means overlapping by 15 days. This is in contrast to the earlier analysis of low-frequency $200-\mathrm{m}$ temperature variability by Stramma and Siedler (1988). They identified an annual temperature variation which they attributed to a seasonal meridional displacement of the northeastern part of the subtropical gyre. If the displacement does not exceed the width of the main gyre flow, the seasonal change would show up in the temperature but not in the current time series.

Also contrary to our observation, Dickson et al. (1982) found a winter maximum in FKE even down to abyssal depths north of $40 \mathrm{~N}$ in the eastern basins, i.e. north of our area of study. They explained their observation as a combined effect of increasing winds and rapidly decreasing stratification during winter in the presence of rough topography. Further south, in our area of study, these mechanisms are much weaker, and therefore baroclinic instability - with no seasonal signal inherent-could be the predominant process and mask any seasonal signal in our records.

Finally we will assemble low-frequency spectra from one main thermocline depth level each of the whole array of moorings in Figure 16. The spectra are from different depth levels between $150 \mathrm{~m}$ and $780 \mathrm{~m}$. They are normalized to compare their shapes, and the total energy is given in the frequency range $1 / 512$ to $1 / 2 \mathrm{~d}^{-1}$. Energy is usually concentrated in the lowest frequency band $1 / 512$ to $1 / 50 \mathrm{~d}^{-1}$, but the energy appears to be spread over a broad range at some sites. It is curious that at both the mooring at the Azores Frontal Zone (KIEL276) and at the Cape Verde Frontal Zone (W3) we find pronounced peaks in the spectrum while there are flat spectra with less energy on both sides of the front ( $U, M o 2$ and $W 4, W 2$, respectively). Apparently baroclinic instability processes at the fronts (Käse et al., 1986; Onken and Klein, 1991) produce mesoscale waves and eddies which will break up into smaller eddies, spreading the energy to higher frequencies. The energy is highest in the source regions at the fronts. 


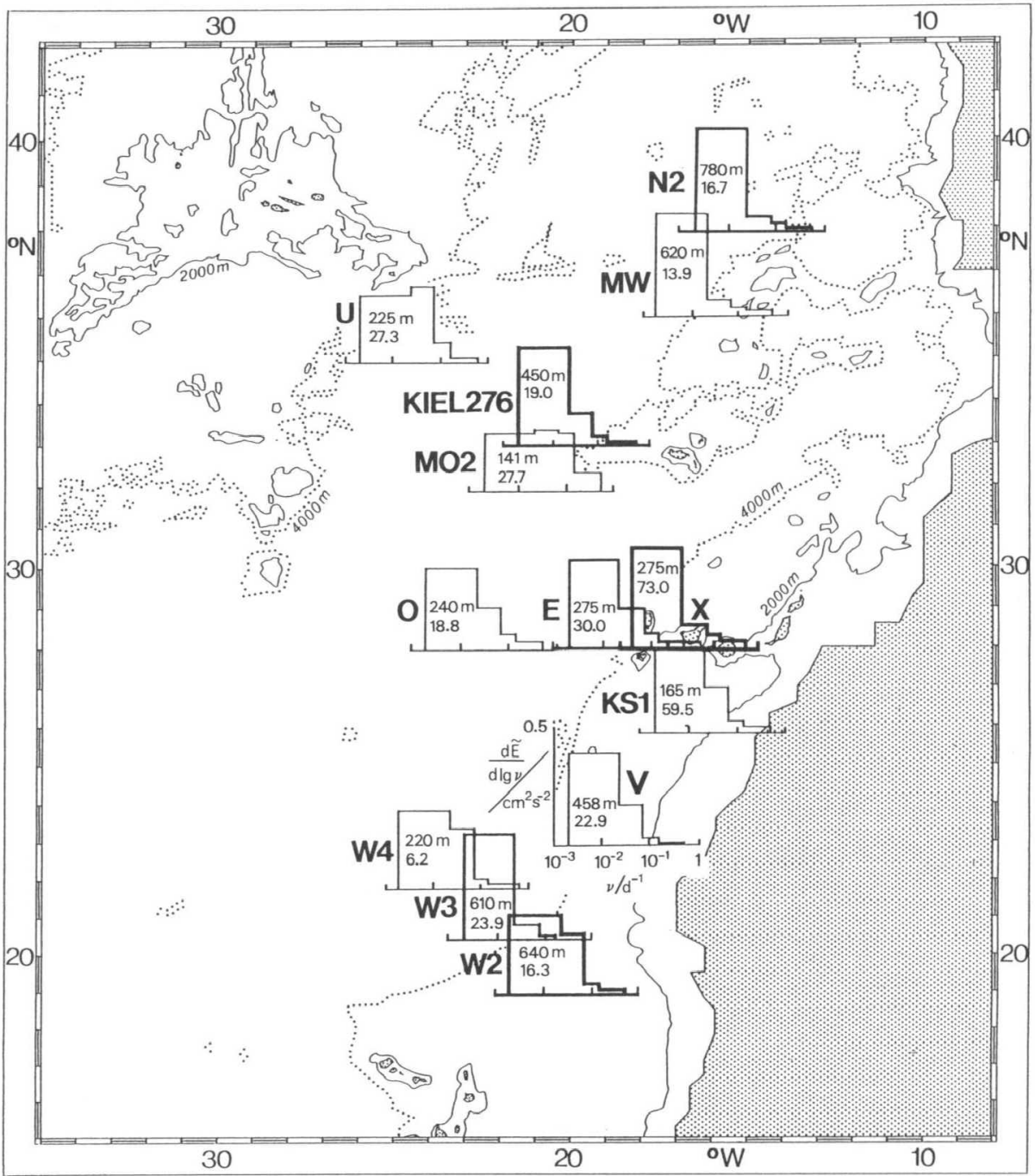

Figure 16. Regional distribution of low-frequency energy spectra in energy-preserving form, normalized by the total variance at each site. The mooring positions are identified by the left edge of the abscissa. The depth level and the total variance in $\mathrm{cm}^{2} \mathrm{~s}^{-2}$ are given by the numbers below the spectral curve. The scale is presented at Site V. For definitions see Figure 13.

\section{Conclusions}

The analysis of the array of moored current meters in the eastern basins of the North Atlantic reveals common features of the low-frequency current variability in this region. We find maximal energy at periods between 1 and 2 months and about 1 year. The energy levels are generally lower here than in the western basins or the North Atlantic. In the 9-year time series from mooring KIEL276 in the Azores 
Frontal Zone we find larger energy in meridional than zonal components in the above range, which can be expected with Rossby wave generation at an eastern boundary. Longer than annual changes at periods of 3-4 years are also discovered in the long time series, primarily in the zonal component. Similar interannual variations have been found in ocean circulation models.

The current variability can be well described by dynamical modes. Typically more than two thirds of the low-frequency energy is provided by the sum of the barotropic and the first-order baroclinic modes or also by one EOF. Because of the strong variability significant mean currents cannot be determined, even with a series of almost 9 years. The behavior of the fluctuating kinetic energy is characterized by events which are typically 2 or 3 times more energetic than the normal energy level. The regional distribution indicates higher energies in frontal regions, in the Canary Current and close to the Canary archipelago. High energies are also encountered because of the existence of Meddies in the North Atlantic Deep Water.

Acknowledgments. The mooring data were provided by the joint effort of many members of the Marine Physics group at the Institut für Meereskunde in Kiel. We thank all those who assisted in the work at sea and in data processing. We particularly want to thank D. Carlsen and co-workers for their excellent contributions to the mooring operations. In the analysis we have benefitted from discussions with R. Käse, J. Willebrand, K. Speer and W. Zenk. The study was funded by the Deutsche Forschungsgemeinschaft (SFB 133). 


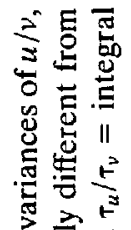

II $\stackrel{3}{\text { 要 }}$

$13 \stackrel{\Xi}{N}$

部

$3 \stackrel{4}{*}$

可 步

$>0$

3 范

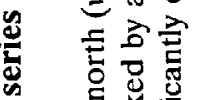

ङ

$+\sqrt{6} \cdot \frac{5}{2}$

ชู 3

둔

E $85 \%$

몬 可

鸟

11 80

$1 \geq 115$

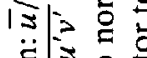

.

๓ 2

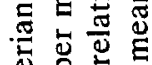

$\stackrel{2}{\circ} \stackrel{0}{=}$

却芯芯

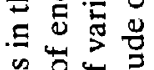

幽步至

3

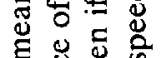

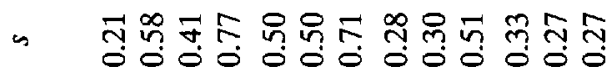

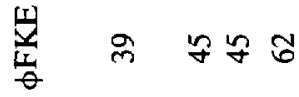

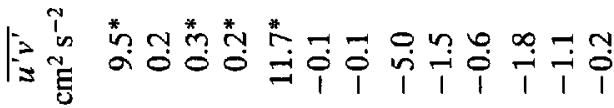

य

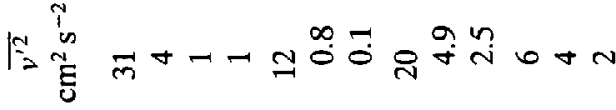

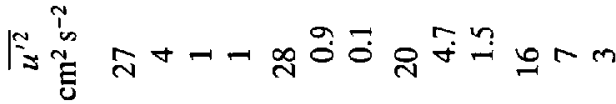

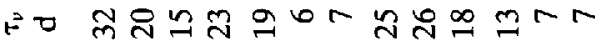

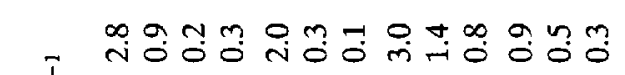
$+1+1+1+1+1+1+1+1+1+1+1+1$

E

$\because \overparen{0}$

65

N

\&

$\bar{\Xi}$

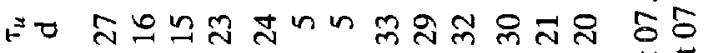

등 흉

$m$ mষ்

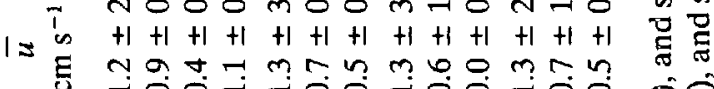

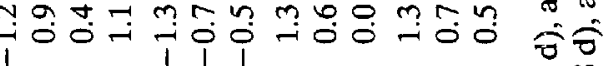

กี

응

$N \infty$

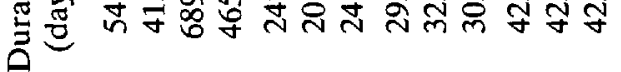

ษ

$Q \sum$

$\stackrel{1}{n}$

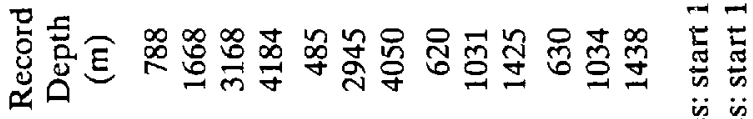

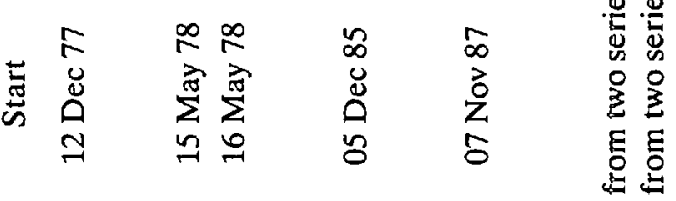

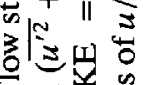

¿1 11 क

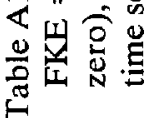

I $\simeq \frac{1}{0}$

․ㅗ를

른

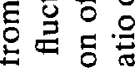

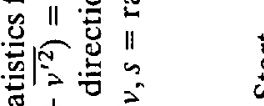

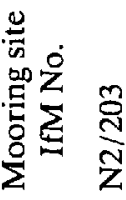

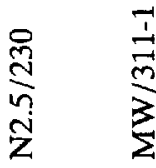

$\sum_{i}^{\frac{1}{m}} \quad \frac{1}{2}$
0

. 등 
n

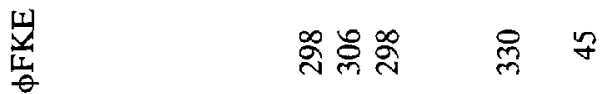

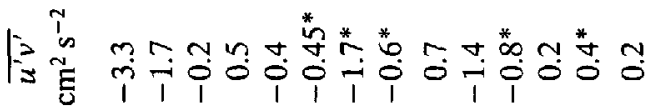

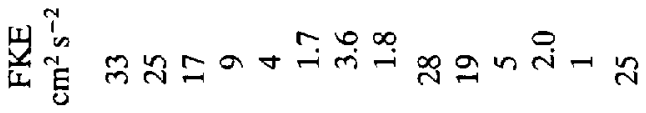

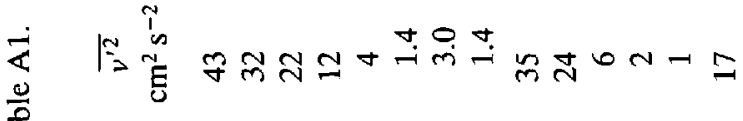

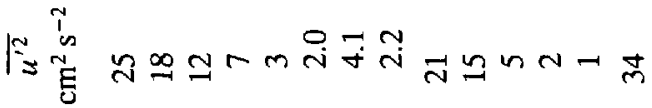

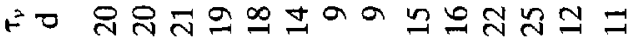

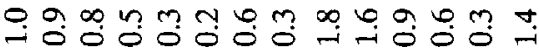

b $1=$ in $+1+1+1+1+1+1+1+1+1+1+1+1+1+1$

产

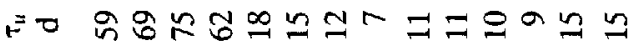

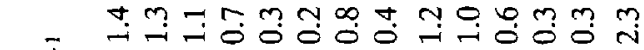

$1=$ is $+1+1+1+1+1+1+1+1+1+1+1+1+1+1$

E

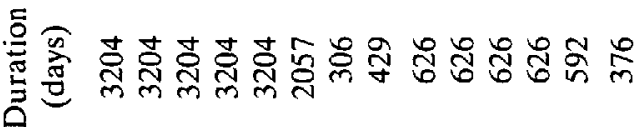

면

E

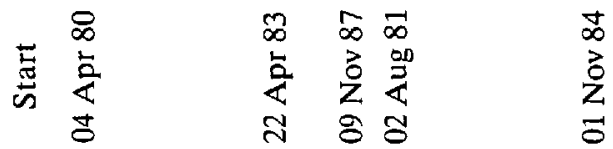

$\frac{9}{5}$

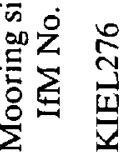

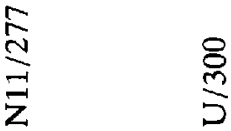


y 莳莳莳

i $\quad$ 㟧 $\approx$

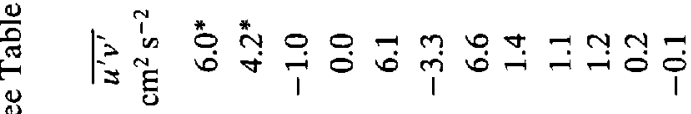

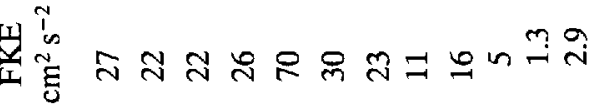

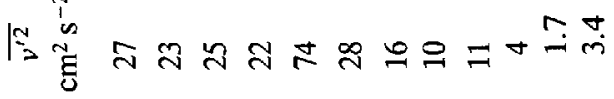

范

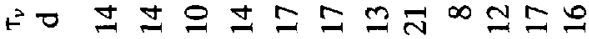

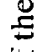

范

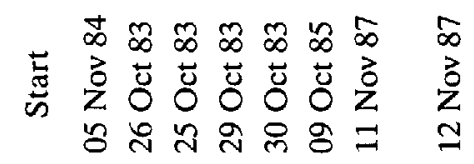


m 귱ㅎㅁ

岁

우

总 $=\stackrel{\infty}{\infty}$

Fi

至䓵

Fîn

部先

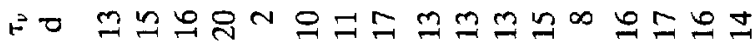

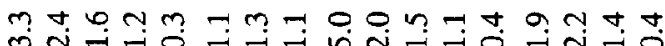

点

.

(3)

莒

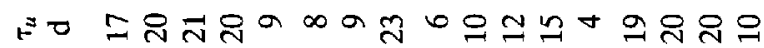

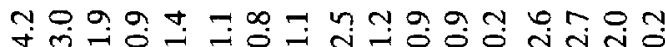
$1=$ is $+1+1+1+1+1+1+1+1+1+1+1+1+1+1+1+1+1$ E 풍

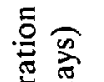

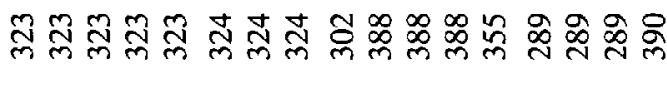
Q $+1+1+1+1+1+1+1+1+1+1+1+1+1+1+1+1+1$

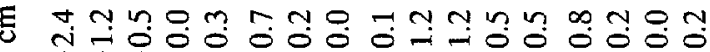
个TiO

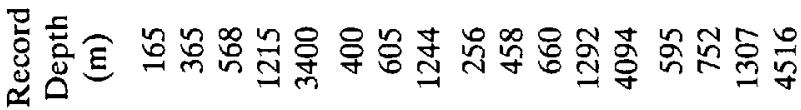
总

矛点

$\$$
$\infty$
$z$
$z$
2

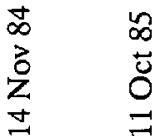

$\infty$

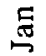

$\infty$

营

商

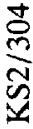

$\frac{5}{>}$

$\frac{\infty}{\partial}$ 


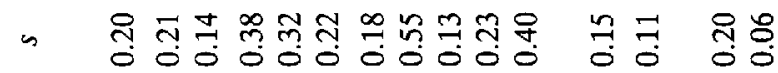

$\frac{1}{\theta} \stackrel{n}{\frac{1}{4}}$

m

$F$ 点

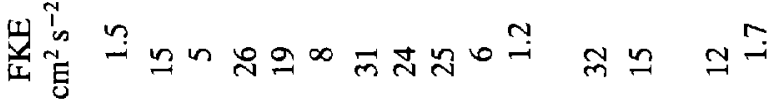

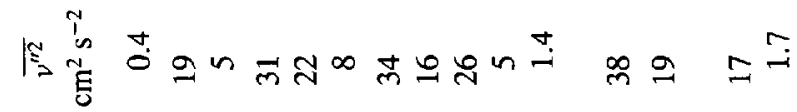

ॠ

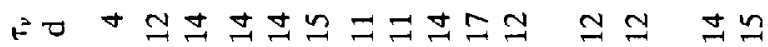

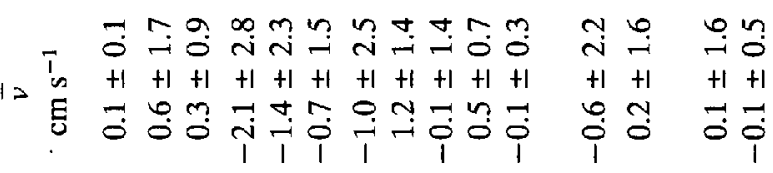

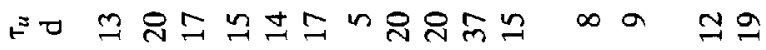

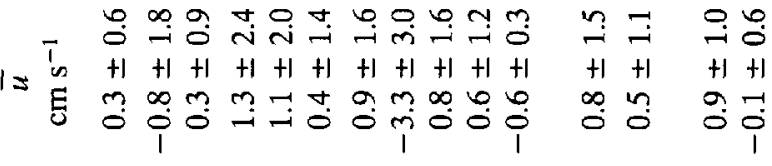

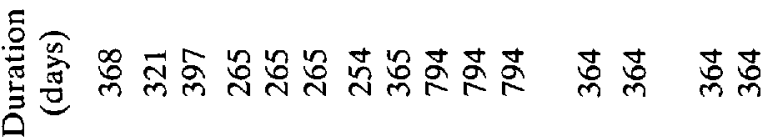

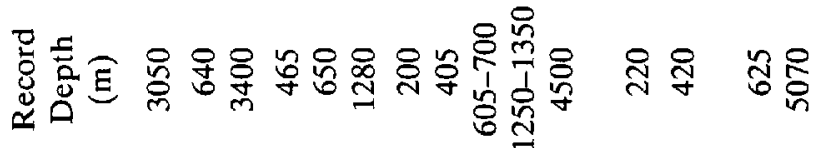

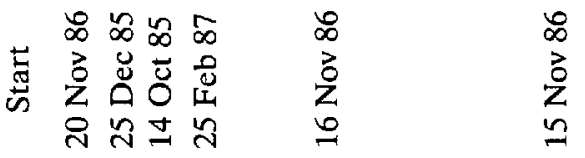

茫 $\stackrel{0}{.}$

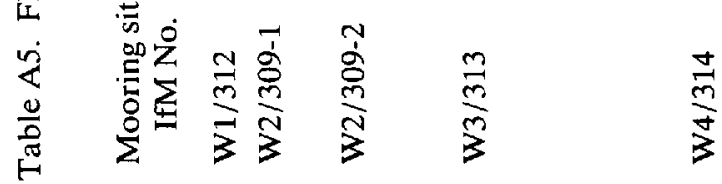




\section{REFERENCES}

Armi, L. and H. Stommel. 1983. Four views of a portion of the North Atlantic subtropical gyre. J. Phys. Oceanogr., 13, 828-857.

Armi, L. and W. Zenk. 1984. Large lenses of highly saline Mediterranean water. J. Phys. Oceanogr., 14, 1560-1576.

Barton, E. D. 1987. Meanders, eddies and intrusions in the thermocline front off Northwest Africa. Oceanol. Acta, 10, 267-282.

Colin de Verdiere, A., H. Mercier and M. Arhan. 1989. Mesoscale variability transition from the Western to the Eastern Atlantic along 48 N. J. Phys. Oceanogr., 19, 1171-1173.

Cox, M. D. 1987. An eddy-resolving numerical model of the ventilated thermocline: Time dependence. J. Phys. Oceanogr., 17, 1044-1056.

Defant, A. 1955. Die Ausbreitung des Mittelmeerwassers im Nordatlantischen Ozean, in Papers in Marine Biology and Oceanography. Deep-Sea Res., 3, (Suppl.), 465-470.

Dick, G. and G. Siedler. 1985. Barotropic tides in the Northeast Atlantic inferred from moored current meter data. Dt. Hydrogr. Z., 38, H1, 7-22.

Dickson, R. R. 1983. Global summaries and intercomparisons: Flow statistics from long-term current meter moorings, in Eddies in Marine Science, A. R. Robinson ed, Springer Verlag, Berlin, 278-375.

1989. World ocean circulation experiment, flow statistics from long-term current-meter moorings, the global data-set in January 1989. WCRP-30 (WMO/TD-No. 337), 35 pp. and 711 tables, World Meteorological Organization, Geneva, 1989.

Dickson, R. R., J. W. Gould, P. A. Gurbutt and P. D. Killworth. 1982. A seasonal signal in occan currents to abyssal depths. Nature, 295, 193-198.

Dickson, R. R., J. W. Gould, T. J. Müller and C. Maillard. 1985. Estimates of the mean circulation in the deep ( $>2000 \mathrm{~m}$ ) layer of the Eastern North Atlantic. Prog. Oceanogr., 14, 103-127.

Fiadeiro, M. E. and G. Veronis. 1982. On the determination of absolute velocities in the ocean. J. Mar. Res., 40, (Suppl.), 159-192.

Flierl, G. R. and J. C. McWilliams. 1977. On the sampling requirements for measuring moments of eddy variability. J. Mar. Res., 35, 797-820.

Fu, L.-L., T. Keffer, P. P. Niiler and C. Wunsch. 1982. Observations of mesoscale variability in the western North Atlantic: A comparative study. J. Mar. Res., 40, 809-848.

Gould, W. J. 1983. The Northeast Atlantic Ocean, in Eddies in Marine Science, Robinson, A.R. ed., Springer-Verlag, Berlin, 145-157.

1985. Physical oceanography of the Azores Front. Prog. Oceanogr., 14, 167-190.

Hagen, E. 1985. A meandering intermediate front north-west off Cape Verde Islands. Océanogr. Trop., 20, 71-83.

Hermann, P. and W. Krauss. 1989. Generation and propagation of annual Rossby waves in the North Atlantic. J. Phys. Oceanogr., 19, 727-744.

Imawaki, S. and K. Takano. 1982. Low-frequency eddy kinetic energy spectrum in the deep western Pacific. Science, 216, 1407-1408.

Inoue, M. 1985. Modal decomposition of low-frequency currents and baroclinic instability at Drake Passage. J. Phys. Oceanogr., 15, 1157-1181.

Isemer, H.-J. and L. Hasse. 1987. The Bunker Climate Atlas of the North Atlantic Ocean. Vol. 2: Air-Sea Interaction, Springer-Verlag, Berlin, 252 pp.

Käse, R. H., J. F. Price, P. L. Richardson and W. Zenk. 1986. A quasi-synoptic survey of the thermocline circulation and water mass distribution in the Canary Basin. J. Geophys. Res., 91, 9739-9748. 
Käse, R. H. and G. Siedler. 1982. Meandering of the subtropical front southeast of the Azores. Nature, 300, 245-246.

Klein, B. and G. Siedler. 1989. On the origin of the Azores Current. J. Geophys. Res., 94, 6159-6168.

Krauss, W. 1986. The North Atlantic Current. J. Geophys. Res., 91, 5061-5074.

Krauss, W. and R. H. Käse. 1984. Mean circulation and eddy kinetic energy in the Eastern North Atlantic. J. Geoph. Res., 89, 3407-3415.

Krauss, W. and C. Wübber. 1982. Response of the North Atlantic to annual wind variations along the eastern coast. Deep-Sea Res., 29, 851-868.

LeBlond, P. H. and L. A. Mysak. 1978. Waves in the Ocean, Elsevier Scient. Publ. Comp., 602 pp.

Lippert, A. and R. H. Käse. 1985. Stochastic wind forcing of baroclinic Rossby waves in the presence of a meridional boundary. J. Phys. Oceanogr., 15, 184-194.

Lorenz, E. N. 1959. Empirical Orthogonal Functions and statistical weather prediction, Final Report Statistical Forecasting Project, Mass. Inst. Techn. Dep. Met., App. I, S. 29-78.

Luyten, J. R. 1982. Equatorial current measurements, I. Moored observations. J. Mar. Res., 40,19-41.

Maillard, C. 1984. Mean circulation and exchanges in the Northeastern Atlantic from historical data. Rapp. Proc.--Verb. Reun., 185, 131-139.

— 1986: Atlas hydrologique de l'atlantique nord-est. IFREMER, Brest, 32 pp. and 133 maps.

McWilliams, J. C. and C. Y. Shen. 1980. Mesoscale modal coupling. J. Phys. Oceanogr., 10, 741-752.

Müller, P. and C. Frankignoul. 1981. Direct forcing of geostrophic eddies. J. Phys. Oceanogr., 11, 287-308.

Müller, T. J. 1987. Analyse niederfrequenter Strömungsschwankungen im Nordostatlantik. Ber. Inst. f. Meereskunde Kiel, Nr. 170, 134 pp.

Müller, T. J., G. Siedler and W. Zenk. 1988. Forschungsschiff METEOR, Reise Nr. 6. ATLANTIK 87/88-Fahrtabschnitte Nr. 1-3, Oktober-Dezember 1987. Berichte der wissenschaftlichen Leiter. Ber. Inst. f. Meereskunde Kiel, Nr. 184, 77 pp.

Müller, T. J., J. Xu, O. Llinas and E. Perez-Martell. 1990. Hydrographic and current observations in the North-East Atlantic Ocean-Data Report F. S. POLARSTERN Cruise ANT IV/lb, F. S. POSEIDON Cruise 124, B.O. TALIARTE Cruise XIV, September to December 1985. Ber. Inst. f. Meereskunde Kiel, No. 202, 105 pp.

Niiler, P. P. and M. M. Hall. 1988. Low-frequency eddy variability at $28 \mathrm{~N}, 152 \mathrm{~W}$ in the eastern North Pacific gyre. J. Phys. Oceanogr., 18, 1670-1685.

Olbers, D. J., M. Wenzel and J. Willebrand. 1985. The inference of North Atlantic circulation patterns from climatological hydrographic data. Rev. Geophys., 23, 313-356.

Onken, R. and B. Klein. 1991. A model of baroclinic instability and waves between the ventilated gyre and the shadow zone of the North Atlantic Ocean. J. Phys. Oceanogr., 21, 53-67.

Owens, W. B., J. R. Luyten and H. L. Bryden. 1982. Moored velocity measurements on the edge of the Gulf-Stream recirculation. J. Mar. Res., 40, (Suppl.), 509-524.

Pedlosky, J. 1979. Geophysical Fluid Dynamics. Springer-Verlag, New York, 624 pp.

Pollard, R. T. and S. Pu. 1985. Structure and circulation of the upper Atlantic Ocean northeast of the Azores. Prog. Oceanogr. 14, 443-462.

Reid, J. L. 1978. On the middepth circulation and salinity field in the North Atlantic Ocean. J. Geophys. Res., 83, 5063-5067. 
Richman, J. G., C. Wunsch and N. G. Hogg. 1977. Space and time scales of mesoscale motion in the Western North Atlantic. Rev. Geophys. Sp. Phys., 15, 385-420.

Saunders, P. M. 1982. Circulation in the eastern North Atlantic. J. Mar. Res., 40, (Suppl.), 641-657.

Schmitz, W. J. 1978. Observations of the vertical distribution of low frequency kinetic energy in the Western North Atlantic. J. Mar. Res., 36, 295-310.

- 1988. Exploration of the eddy field in the midlatitude North Pacific. J. Phys. Oceanogr., $18,459-468$.

1989. The MODE site revisited. J. Mar. Res., 45, 131-151.

Schmitz, W. J., and N. G. Hogg. 1978. Observations of energetic low frequency current fluctuations in the Charly-Gibbs-Fracture-Zone. J. Mar. Res., 36, 725-734.

Schmitz, W. J., Jr., J. F. Price and P. L. Richardson. 1988. Recent moored current meter and SOFAR float observations in the eastern Atlantic near 32N, J. Mar. Res., 46, 301-319.

Siedler, G., A. Kuhl and W. Zenk. 1987. The Madeira Mode Water. J. Phys. Oceanogr., 17, 1561-1570.

Siedler, G. and U. Paul. 1991. Barotropic and baroclinic tidal currents in the eastern basins of the North Atlantic. J. Geophys. Res., 96, 22,259-22,271.

Siedler, G., H. Schmickler, T. J. Müller, H.-W. Schenke and W. Zenk. 1987. Forschungsschiff "Meteor," Reise Nr. 4, Berichte der wissenschaft lichen Leiter. Inst. f. Meereskunde Kiel, Nr. 173, 123 pp.

Siedler, G. and L. Stramma. 1983. The applicability of the T/S method to geopotential anomaly computations in the Northeast Atlantic. Oceanologica Acta, 6, 167-172.

Sicdler, G., W. Zenk and W. J. Emery. 1985. Strong current events related to a subtropical front in the Northeast Atlantic. J. Phys. Oceanogr., 15, 885-897.

Spall, M. A. 1990. Circulation in the Canary Basin: A model/data analysis. J. Geophys. Res., 95, 9611-9628.

Stramma, L. 1984a. Wassermassenausbreitung in der Warmwassersphäre des subtropischen Nordostatlantiks. Ber. Inst. Meereskd. Univ. Kiel, No. 12, 108 pp.

- 1984b. Geostrophic transport in the Warm Water Sphere of the eastern subtropical North Atlantic. J. Mar. Res., 42, 537-558.

Stramma, L. and H.-J. Isemer. 1988. Seasonal variability of meridional temperature fluxes in the eastern North Atlantic Ocean. J. Mar. Res., 46, 281-299.

Stramma, L. and T. J. Müller. 1989. Some observations of the Azores Current and the North Equatorial Current. J. Geophys. Res., 94, 3181-3186.

Stramma, L. and G. Siedler. 1988. Seasonal changes in the North Atlantic subtropical gyre. J. Geophys. Res., 93, 8111-8118.

Sturges, W. 1983. On interpolating gappy records from time series analysis. J. Geoph. Res., 88, 9736-9740.

Sy, A. 1988. Investigation of large-scale circulation patterns in the central North Atlantic: the North Atlantic Current, the Azores Current, and the Mediterranean Water plume in the area of the Midatlantic Ridge. Deep-Sea Res., 35, 383-413.

The MODE Group. 1978. The Mid Ocean Dynamics Experiment. Deep-Sea Res., 25, 859-910.

Thiele, G., W. Roether, P. Schlosser, R. Kuntz, G. Siedler and L. Stramma. 1986. Baroclinic flow and transient-tracer fields in the Canary-Cape-Verde Basin. J. Phys. Oceanogr., 16, 814-826.

Tomczak, M. Jr. 1981. An analysis of mixing in the frontal zone of South and North Atlantic Central Water off North-West Africa. Progr. Oceanogr., 10, 173-191. 
VanGriescheim, A. 1988. Deep layer variability in the eastern North Atlantic: the EDYLOC experiment. Oceanologica Acta, 11, 149-158.

Wunsch, C. 1981. Low-frequency variability of the sea, in Evolution in Physical Oceanography, B. C. Warren, and C. Wunsch eds., MIT Press, 342-374.

1983. Western North Atlantic interior, in Eddies in Marine Science, A. R. Robinson ed, Springer-Verlag, Berlin, 46-65.

Zenk, W., B. Klein and M. Schröder. 1991. Cape Verde Frontal Zone. Deep-Sea Res., 38, (Suppl.) S505-S530.

Zenk, W. and T. J. Müller. 1988. Seven-year current meter record in the eastern North Atlantic. Deep-Sea Res., 35, 1259-1268.

Zenk, W., T. J. Müller and G. Wefer. 1989. BARLAVENTO-Expedition, Reise Nr. 9, 29. Dez. 1988-17. März 1989. METEOR-Berichte, Universität Hamburg, 89-2, 238 pp. 